TI 2013-035/V

Tinbergen Institute Discussion Paper
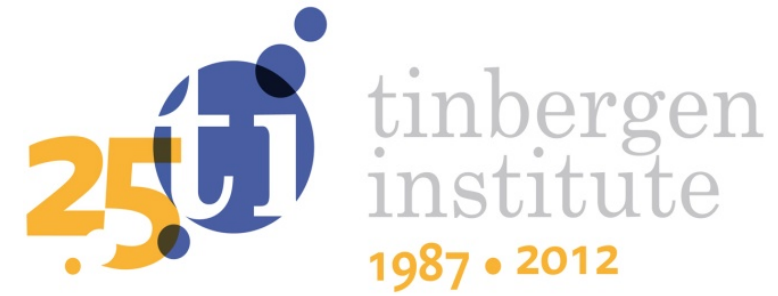

Why the Rich drink More but smoke

Less:

\title{
The Impact of Wealth on Health Behaviors
}

Hans van Kippers/uis'

Titus J. Galama²

' Erasmus School of Economics, Erasmus University Rotterdam, Tinbergen Institute; 2 University of Southern California, Dornsife College Center for Economic and Social Research \& RAND Corporation, USA. 
Tinbergen Institute is the graduate school and research institute in economics of Erasmus University Rotterdam, the University of Amsterdam and VU University Amsterdam.

More TI discussion papers can be downloaded at http://www.tinbergen.nl

Tinbergen Institute has two locations:

Tinbergen Institute Amsterdam

Gustav Mahlerplein 117

1082 MS Amsterdam

The Netherlands

Tel.: +31(0)205251600

Tinbergen Institute Rotterdam

Burg. Oudlaan 50

3062 PA Rotterdam

The Netherlands

Tel.: +31(0)10 4088900

Fax: $+31(0) 104089031$

Duisenberg school of finance is a collaboration of the Dutch financial sector and universities, with the ambition to support innovative research and offer top quality academic education in core areas of finance.

DSF research papers can be downloaded at: http://www.dsf.nl/

Duisenberg school of finance

Gustav Mahlerplein 117

1082 MS Amsterdam

The Netherlands

Tel.: +31(0)20 5258579 


\title{
Why the Rich Drink More but Smoke Less: The Impact of Wealth on Health Behaviors*
}

\author{
Hans van Kippersluis ${ }^{\dagger} \quad$ Titus J. Galama ${ }^{\ddagger}$
}

February 26, 2013

\begin{abstract}
Wealthier individuals engage in healthier behavior. This paper seeks to explain this phenomenon by developing a theory of health behavior, and exploiting both lottery winnings and inheritances to test the theory. We distinguish between the direct monetary cost and the indirect health cost (value of health lost) of unhealthy consumption. The health cost increases with wealth and the degree of unhealthiness, leading wealthier individuals to consume more healthy and moderately unhealthy, but fewer severely unhealthy goods. The empirical evidence presented suggests that differences in health costs may indeed provide an explanation for behavioral differences, and ultimately health outcomes, between wealth groups.
\end{abstract}

Keywords: consumption, health, health capital, health behavior, wealth

JEL Codes : D91, I10, I12, I14, J24

\footnotetext{
${ }^{*}$ Research reported in this publication was supported by the National Institute on Aging of the National Institutes of Health under Award Numbers R01AG030824, K02AG042452, R01AG037398 and P01AG022481. The content is solely the responsibility of the authors and does not necessarily represent the official views of the National Institutes of Health. We thank Netspar for support on the theme "Health and Income, Work and Care across the Lifecycle II". Titus Galama is grateful to the School of Economics of Erasmus University Rotterdam for a Visiting Professorship in the Economics of Human Capital. We thank Marco Angrisani, Pilar Garcia-Gomez, Arie Kapteyn, Erik Meijer, Owen O'Donnell, Rosalie Pacula, Bastian Ravesteijn, James Smith, Darjusch Tafreschi, Eddy van Doorslaer, and Tom Van Ourti for helpful discussions.

${ }^{\dagger}$ Erasmus School of Economics, Erasmus University Rotterdam (EUR), and Tinbergen Institute, The Netherlands.

${ }^{\ddagger}$ University of Southern California, Dornsife College Center for Economic and Social Research, USA, and RAND Corporation, USA.
} 


\section{Introduction}

Unhealthy lifestyles and unhealthy consumption are more prevalent among the poor, and account for a large fraction of the substantial socioeconomic disparities in health (Contoyannis and Jones 2004; Cutler et al. 2011). More affluent individuals are less likely to smoke, drink heavily, be overweight, and use illegal drugs, and are more likely to exercise and engage in preventive care (e.g., Cutler and Lleras-Muney 2010; Cutler et al. 2011). A phenomenon of particular interest is that richer people tend to engage more in moderately unhealthy behaviors, such as drinking moderately, ${ }^{1}$ but less in severely unhealthy behaviors, such as excessive alcohol consumption (Cutler and Lleras-Muney 2010). What explains these differences in health behaviors across wealth groups remains largely unclear (Cutler et al. 2011).

The lack of understanding of the causes of observed differences in health behavior across wealth groups may be due to two main limitations of the existing literature. First, theoretical models of consumption and saving have difficulty explaining differences in (un)healthy consumption across wealth groups. In these models, wealth enables more consumption, and the quantity purchased is governed by the monetary price of the good, permanent income and wealth, as well as preferences. Unless preferences differ substantially, these models would predict that wealthier individuals would engage more, not less, in unhealthy consumption. A second limitation is that empirical findings are usually limited to correlations, and are not necessarily indicative of a causal effect of wealth or income on health behaviors. ${ }^{2}$

This paper attempts to address both the theoretical and empirical limitations. We present a theory of health behavior based on the human capital theory of the demand for health investment (Grossman 1972). By explicitly considering the health consequences of consumption, our health-capital theory predicts differences in health behaviors across wealth groups and provides a possible explanation for the observation that wealthy individuals are less likely to drink excessively but more likely to drink moderately (e.g., Cutler et al. 2011).

According to our theory, the decision to engage in unhealthy consumption is governed by the monetary cost (i.e. the price of a pack of cigarettes) as well as a health cost (i.e. value of health lost). The model predicts that wealth has two effects. First, there is the familiar direct effect: wealth allows individuals to purchase more (unhealthy) consumption goods. But there is also an indirect effect: the health cost increases in the "unhealthiness" of the good and in health investment, and is therefore higher for wealthier individuals and for more severely unhealthy goods. The direct and the indirect wealth

\footnotetext{
${ }^{1}$ Some studies suggest that drinking moderately may be beneficial to one's health (e.g., Fuller 2011).

${ }^{2}$ Related to our research, studies have shown that smoking and drinking may affect wages (e.g., Auld 2005; Cawley and Ruhm 2011), and so reverse causality from health behaviors to wealth may be present. Also factors such as the degree of cognition, forward orientation (time preference), risk aversion, etc. may simultaneously influence wealth and health behaviors causing a spurious association. In this paper we focus solely on causality running from wealth to health behaviors.
} 
effect compete and while the net effect is ambiguous, wealthy individuals are likely to engage more in moderately (direct wealth effect dominates) and less in severely unhealthy consumption (indirect health cost effect dominates). The theory can thus provide a possible explanation for the observed positive association between wealth and moderately unhealthy consumption and the negative association with severely unhealthy consumption. Our theory further predicts that the strength of the response to an unexpected wealth shock is smallest for the wealthy and for a high degree of unhealthiness of the consumption good, and that health and age also matter in decisions regarding unhealthy consumption goods.

The second part of the paper employs the theory to inform the empirical specifications and estimates the effect of wealth on healthy and unhealthy consumption for different wealth, health and age groups. In doing so, we contribute to a relatively small literature which seeks to estimate the effect of variation in wealth or income on health behavior. ${ }^{3}$ Ettner (1996) exploits state unemployment rates, work experience, parental education, and spousal characteristics as instruments for income using US data. She finds that the probability of drinking any alcohol increases with income, although the validity of the instruments used has been questioned (e.g., Kawachi et al. 2010). Adda et al. (2009) exploit skill-based technology changes in income at the cohort level using three English repeated cross-sectional surveys. The authors report that permanent income shocks lead to poorer health behavior - an increase in the number of cigarettes smoked, in the probability of being a smoker, and in alcohol consumption. Kenkel et al. (2011) exploit the Earned Income Tax Credit (EITC) - the United States' second largest antipoverty program for the non-elderly, which showed considerable variation in timing and benefit level across states over the years 1993 to 2007 - to estimate the impact of sudden shocks in disposable income among low-income households. They find an increase in smoking participation upon a positive income shock.

Apouey and Clark (2010) use lottery winnings from the British Household Panel Survey (BHPS) and find that those who win higher amounts are more likely to smoke and engage in social drinking. Kim and Ruhm (2012) use the US Health and Retirement Study (HRS) to distinguish between small and big inheritances, where small inheritances are defined as those below $\$ 10,000$ US dollars. They identify wealth shocks on the basis of "large" inheritances, and find that wealth shocks increase out-of-pocket medical expenditures and alcohol consumption, but do not affect smoking or exercising. Yet, for both studies there may be unobserved differences across those that receive large and small amounts from either a lottery win or an inheritance that is not accounted for.

We contribute to the empirical literature in three ways. First, we use a more conservative and robust approach than the extant literature by including individual-specific fixed effects, by estimating a number of different specifications, and exploiting both lottery winnings and inheritances. Second, in contrast to previous work,

\footnotetext{
${ }^{3}$ We here review the literature that investigates the effect of wealth on health behaviors, as this is the main focus of our paper. A related literature has investigated the effect of wealth on health outcomes (e.g., Adams et al. 2003; Meer et al. 2003; Lindahl 2005; Snyder and Evans 2006; Schwandt 2011).
} 
we focus on detailed analyses of subgroups. Motivated by the predictions of our theory we explore differences in health behavior among wealth, health and age groups. In particular, our aim is to examine our hypothesis that health costs matter in decisions regarding health behavior. Third, we replicate the analyses of Apouey and Clark (2010) and Kim and Ruhm (2012) and present evidence suggesting that their prior estimates of the causal impact of wealth on health behaviors may not have fully accounted for unobserved heterogeneity.

The empirical evidence suggests that differences in health costs may provide an explanation for observed behavioral differences between wealth groups. A wealth increase leads to more moderately unhealthy consumption such as moderate drinking for all individuals, but no change in heavy drinking. The effects on severely unhealthy consumption, such as smoking and the number of cigarettes, are stronger among the least wealthy. The findings further suggest that health status is very important in explaining health behavior: only among individuals in good health do we find strong increases in unhealthy behavior, suggesting that the health cost of unhealthy consumption is smaller among the healthy.

The paper is organized as follows. Section 2 formulates a theory of wealth, health and consumption patterns, and discusses predictions. Section 3 presents the data and empirical methodology. Section 4 presents the results, and section 5 provides a summary and discussion.

\section{A theory of wealth, health, and unhealthy consumption}

\subsection{Theoretical formulation}

Our model is based on Galama and Van Kippersluis (2010), and builds on the human capital theory of the demand for health investment (Grossman 1972) with two important extensions. First, we use a health production process that is subject to diminishing returns to scale. This addresses the indeterminacy of the solutions for investment and health that characterizes commonly employed linear investment models (Ehrlich and Chuma 1990; Galama 2011). It is further attractive in that the health investment process is generally thought of as being subject to diminishing returns (Wagstaff 1986). Second, we explicitly model the effect of consumption on health through its effect on the biological aging rate. ${ }^{4}$ We distinguish healthy consumption (such as the consumption of healthy foods, sports and exercise) from unhealthy consumption (such as smoking, excessive alcohol consumption). Healthy consumption provides utility and is associated with health benefits in that it lowers the biological aging rate. Unhealthy consumption provides utility but increases the biological aging rate.

\footnotetext{
${ }^{4}$ Forster (2001) and Case and Deaton (2005) have also modeled unhealthy consumption as a choice variable affecting health deterioration. In these models, the price of unhealthy consumption is solely in terms of the consequences to health, i.e. there is no monetary cost of unhealthy consumption and thus no direct wealth effect.
} 
Individuals maximize the life-time utility function

$$
\int_{0}^{T} U\left[C_{h}(t), C_{u}(t), H(t)\right] e^{-\beta t} d t
$$

where $T$ denotes the life span, assumed exogenous for $\operatorname{simplicity,}^{5} \beta$ is a subjective discount factor and individuals derive utility from healthy consumption $C_{h}(t)$, unhealthy consumption $C_{u}(t)$ and from health $H(t)$. Time $t$ is measured from the time an individual has completed her education and joined the labor force. Utility increases with healthy consumption $\partial U / \partial C_{h}>0$, unhealthy consumption $\partial U / \partial C_{u}>0$, and with health $\partial U / \partial H>0$, but at a decreasing rate $\partial^{2} U / \partial C_{h}^{2}<0, \partial^{2} U / \partial C_{u}^{2}<0$, and $\partial^{2} U / \partial H^{2}<0$.

The objective function (1) is maximized subject to the following dynamic equations, ${ }^{6}$

$$
\begin{aligned}
\dot{H}(t) & =\mu_{I}(t) I(t)^{\alpha}-d\left[t, C_{h}(t), C_{u}(t) ; \xi(t)\right] H(t), \\
\dot{A}(t) & =\delta A(t)+Y[H(t)]-p_{C_{h}}(t) C_{h}(t)-p_{C_{u}}(t) C_{u}(t)-p_{I}(t) I(t),
\end{aligned}
$$

and we have initial and end conditions: $H(0), H(T), A(0)$ and $A(T)$ are given.

$\dot{H}(t)$ and $\dot{A}(t)$ in equations (2) and (3) denote time derivatives of health $H(t)$ and assets $A(t)$. Health (equation 2) can be improved through investment in health $I(t)$, and deteriorates at the biological aging rate $d(t)$. The health-production function $\mu_{I}(t) I(t)^{\alpha}$ has an efficiency $\mu_{I}(t)$, and exhibits diminishing returns to scale (DRTS; $0<\alpha<1$ ). The biological aging rate depends endogenously on healthy consumption $C_{h}(t)$ and unhealthy consumption $C_{u}(t)$, and on a vector of exogenous variables $\xi(t)$ (e.g., environmental conditions). Consumption can be healthy $\left(\partial d / \partial C_{h} \leq 0\right)$ or unhealthy $\left(\partial d / \partial C_{u}>0\right)$.

Assets $A(t)$ (equation 3) provide a return $\delta$ (the return to capital), increase with income $Y(t)$ and decrease with purchases of healthy consumption goods $C_{h}(t)$, unhealthy consumption goods $C_{u}(t)$, and health investment $I(t)$, at prices $p_{C_{h}}(t), p_{C_{u}}(t)$, and $p_{I}(t)$, respectively. Income $Y(t)$ is assumed to be an increasing and concave function of health $H(t)\left(\partial Y / \partial H>0\right.$, and $\left.\partial^{2} Y / \partial H^{2}<0\right)$. Last, we assume that individuals face no borrowing constraints.

Thus, we have the following optimal control problem: the objective function (1) is maximized with respect to the control functions $C_{h}(t), C_{u}(t)$, and $I(t)$, subject to the constraints (2) and (3). The Hamiltonian (see, e.g., Seierstad and Sydsaeter 1987) of this problem is:

$$
\Im=U(t) e^{-\beta t}+q_{H}(t) \dot{H}(t)+q_{A}(t) \dot{A}(t),
$$

where $q_{H}(t)$ is the marginal value of health $H(t)$ (in utils per unit of health) and $q_{A}(t)$ is the marginal value of assets $A(t)$ (in utils per monetary unit).

\footnotetext{
${ }^{5}$ The predictions for a model including endogenous life span are similar. See Galama and Van Kippersluis (2010) for detail.

${ }^{6}$ For simplicity of exposition, we omit the time components and time constraint in the production of consumption and health investment. The theoretical predictions with respect to wealth are unaffected. See Galama and Van Kippersluis (2010) for the full model.
} 


\section{$2.2 \quad$ First-order conditions}

Derivations of the first-order conditions can be found in appendix A. The first-order condition for maximization of (4) with respect to the control function health investment can be written as

$$
\frac{\partial \pi_{I}(t)}{\partial t}=\pi_{I}(t)[d(t)+\delta]-\left[\frac{1}{q_{A}(0)} \frac{\partial U}{\partial H} e^{-(\beta-\delta) t}+\frac{\partial Y}{\partial H}\right]
$$

where $q_{A}(0)$ is the marginal value (or shadow prize) of initial wealth, and $\pi_{I}(t)$ is the marginal cost of health investment $I(t)$

$$
\pi_{I}(t) \equiv \frac{p_{I}(t) I(t)^{1-\alpha}}{\alpha \mu_{I}(t)} .
$$

The marginal cost of health investment increases with the price of investment goods and services $p_{I}(t)$ and with the level of investment $I(t)$, due to DRTS in the health production process $\mu_{I}(t) I(t)^{\alpha}(0<\alpha<1$; see equation 2$)$.

The first-order condition for maximization of (4) with respect to the control function healthy consumption is

$$
\frac{\partial U}{\partial C_{h}}=q_{A}(0)\left[p_{C_{h}}(t)-\varphi_{d C_{h}}(t)\right] e^{(\beta-\delta) t}
$$

where $p_{C_{h}}(t)$ is the price of healthy consumption $C_{h}(t)$, representing the direct monetary cost of consumption, and $\varphi_{d C_{h}}(t)$ is the marginal health benefit of healthy consumption

$$
\varphi_{d C_{h}}(t) \equiv-\pi_{I}(t) \frac{\partial d}{\partial C_{h}} H(t)
$$

The marginal health benefit of healthy consumption $\varphi_{d C_{h}}(t)$ represents the marginal monetary value of health saved: it is the product of the marginal cost of health investment $\pi_{I}(t)$ and the marginal amount of health "saved" $\left[\partial d(t) / \partial C_{h}(t)\right] H(t)$. The marginal health benefit can be understood intuitively as the savings in health investment that would have had to be made if consumption had no effect on health. ${ }^{7}$ Compared to a model in which consumption has no health consequences, the "full" price (marginal cost) of healthy consumption is lower because of its health benefit (see 7).

\footnotetext{
${ }^{7}$ An alternative interpretation of the first-order condition for healthy consumption (7) follows from rewriting it as

$$
\frac{\partial U}{\partial C_{h}} e^{-\beta t}+q_{H}(t)\left[-\frac{\partial d}{\partial C_{h}}\right] H(t)=q_{A}(t) p_{C_{h}}(t) .
$$

Thus the optimality condition requires the sum of the discounted marginal benefit of consumption (discounted marginal utility) and the marginal health benefit (the marginal value of health $q_{H}(t)$ times the marginal amount of health "saved" $\left.-\left[\partial d / \partial C_{h}\right] H(t)\right)$ to equal the marginal cost of consumption (the marginal value of wealth $q_{A}(t)$ times the marginal reduction in wealth, i.e. the price of consumption $\left.p_{C_{h}}(t)\right)$.
} 
Similarly, the first-order condition for maximization of (4) with respect to the control function unhealthy consumption is

$$
\frac{\partial U}{\partial C_{u}}=q_{A}(0)\left[p_{C_{u}}(t)+\pi_{d C_{u}}(t)\right] e^{(\beta-\delta) t},
$$

where $p_{C_{u}}(t)$ is the price of unhealthy consumption $C_{u}(t)$ (direct monetary cost) and $\pi_{d C_{u}}(t)$ is the marginal health cost of unhealthy consumption

$$
\pi_{d C_{u}}(t) \equiv \pi_{I}(t) \frac{\partial d}{\partial C_{u}} H(t)
$$

Compared to a model in which consumption has no health consequences, the "full" price (marginal cost) of unhealthy consumption is higher because of its health cost (monetary value of health lost; see 10).

\subsection{Predictions}

In order to predict the effect of an unanticipated wealth shock we compute the comparative dynamic effect of an infinitesimally small change in initial wealth $A_{0}$. The comparative dynamic effect is obtained by taking the derivative of the first-order conditions (5), (7), and (10), and the dynamic health equation (2) with respect to $A_{0}$.

Assuming first-order effects dominate higher-order effects, ${ }^{8}$ the comparative dynamic effect of initial wealth on healthy consumption can be summarized as (see Appendix B for detail):

$$
\frac{\partial C_{h}}{\partial A_{0}}=\lambda_{C_{h}}(t) \times\left[\frac{U_{C_{h}}}{q_{A}(0)} \frac{\partial q_{A}(0)}{\partial A_{0}}-\frac{\varphi_{d C_{h}}(t)}{\pi_{I}(t)} \frac{\partial \pi_{I}}{\partial A_{0}}-\frac{\varphi_{d C_{h}}(t)}{H(t)} \frac{\partial H}{\partial A_{0}}\right]
$$

where $\lambda_{C_{h}}(t)=\left[U_{C_{h} C_{h}}-q_{A}(0) \pi_{I}(t) d_{C_{h} C_{h}} H(t) e^{(\beta-\delta) t}\right]^{-1}<0,{ }^{9} U_{x}=\partial U / \partial x, U_{x x}=$ $\partial^{2} U / \partial x^{2}, d_{x x}=\partial^{2} d / \partial x^{2}$, and the marginal health benefit $\varphi_{d C_{h}}(t)$ is defined in (8). Thus, the impact of wealth on healthy consumption can be decomposed into the impact of wealth on (i) the marginal value of lifetime wealth $q_{A}(0)$, (ii) the marginal cost of health investment $\pi_{I}(t)$, and (iii) the health stock $H(t)$.

The first term between brackets on the RHS of equation (12) represents the direct wealth effect, which is positive under the assumption of diminishing returns to wealth $\left(\partial q_{A}(0) / \partial A_{0}<0\right)^{10}$ : an increase in wealth allows more healthy consumption. Yet, wealth

\footnotetext{
${ }^{8}$ This amounts to assuming that, for example, the direct effect of a change in wealth on healthy consumption is larger than the indirect effect of wealth on unhealthy consumption and unhealthy consumption in turn on healthy consumption.

${ }^{9}$ This would be true under the plausible assumptions of diminishing marginal utility of healthy consumption $\left(U_{C_{h} C_{h}}<0\right)$ and diminishing marginal health benefit of healthy consumption $\left(d_{C_{h} C_{h}}>0\right)$.

${ }^{10}$ This assumption is commonly employed in the literature and implies that lifetime utility has diminishing returns to wealth, i.e. $\frac{\partial q_{A}(0)}{\partial A_{0}}=\frac{\partial^{2}}{\partial A_{0}^{2}} \int_{0}^{T} U(*) e^{-\beta t}<0$, where $U(*)$ is the maximized utility function (see, e.g., Caputo 2005).
} 
also has an indirect effect through the second and third term between brackets on the RHS. In appendix B we show that an increase in wealth leads to a higher marginal cost of health investment $\pi_{I}(t)$ (wealth leads to higher health investment and therefore a higher marginal cost of investment; see equation (6)), at least initially, and better health $H(t)$. Given the coefficients in (12), in particular $\lambda_{C_{h}}(t)<0$ and $\varphi_{d C_{h}}(t)>0$, both the direct and indirect effects operate in the same direction, and the initial response to an increase in wealth is to increase demand for healthy consumption: $\frac{\partial C_{h}}{\partial A_{0}}>0$.

The comparative dynamic effect of initial wealth on unhealthy consumption can be summarized as (see Appendix B for detail):

$$
\frac{\partial C_{u}}{\partial A_{0}}=\lambda_{C_{u}}(t) \times\left[\frac{U_{C_{u}}}{q_{A}(0)} \frac{\partial q_{A}(0)}{\partial A_{0}}+\frac{\pi_{d C_{u}}(t)}{\pi_{I}(t)} \frac{\partial \pi_{I}}{\partial A_{0}}+\frac{\pi_{d C_{u}}(t)}{H(t)} \frac{\partial H}{\partial A_{0}}\right],
$$

where $\lambda_{C_{u}}(t)=\left[U_{C_{u} C_{u}}-q_{A}(0) \pi_{I}(t) d_{C_{u} C_{u}} H(t) e^{(\beta-\delta) t}\right]^{-1}<0 .{ }^{11}$ and the marginal health $\operatorname{cost} \pi_{d C_{u}}(t)$ is defined in (11). Similar to healthy consumption, additional wealth enables purchases of more unhealthy consumption goods - the direct wealth effect (first term on the RHS of 13). Yet, additional wealth also increases the marginal cost of health investment $\pi_{I}(t)$ and health $H(t)$ and thus the marginal health cost of unhealthy consumption $\pi_{d C_{u}}(t)$ (the indirect wealth effect; second and third term between brackets on the RHS of 13): the indirect wealth effect competes with the direct wealth effect.

While we cannot a priori sign the relation between unhealthy consumption and wealth, the two competing effects predict an interesting pattern of behavior. The health cost increases in the severity of its impact on health, $\pi_{d C_{u}(t)} \propto \frac{\partial d}{\partial C_{u}}$ (the degree of "unhealthiness" of the consumption good). This suggests that for moderately unhealthy goods the direct wealth effect might dominate, while for severely unhealthy goods the indirect wealth effect might dominate. This implies that an increase in wealth may lead to increased demand for moderately unhealthy consumption goods and reduced demand for severely unhealthy consumption goods.

We also expect the impact of a wealth shock on unhealthy consumption to be smaller among wealthier individuals for two reasons. First, the direct effect of a given absolute wealth shock is smaller among wealthier individuals (diminishing returns to wealth). Second, wealthier individuals invest more in health, are in better health, and as a result have a higher health cost for a given degree of "unhealthiness" of the good. The larger the health cost compared to the monetary cost, the smaller the behavioral response is toward a wealth shock. This is because the direct wealth effect operates primarily through the marginal value of wealth $q_{A}(t)$ in the expression for the monetary cost $q_{A}(t) p_{C_{u}}(t)$, which

\footnotetext{
${ }^{11}$ This amounts to assuming diminishing marginal utility of unhealthy consumption $\left(U_{C_{u} C_{u}}<0\right)$ and constant or increasing returns to scale in the health cost of unhealthy consumption (i.e. $d_{C_{u} C_{u}} \geq 0$ ), or that the term $q_{A}(0) \pi_{I}(t) d_{C_{u} C_{u}} e^{(\beta-\delta) t}$ is small compared to $U_{C_{u} C_{u}}$. It is plausible that the health cost of unhealthy consumption exhibits constant or increasing returns to scale (e.g., Forster 2001). In contrast to healthy consumption, which has a natural upper bound to the amount of health it can produce, the health detriment of unhealthy consumption has no natural lower bound. In simplistic terms, consuming fruits and vegetables does not lead to eternal life, but smoking does kill.
} 
is a first-order effect (i.e., responsive to changes in wealth), while the indirect health cost effect operates primarily through the marginal value of health $q_{H}(t)$ in the expression for the health cost $q_{H}(t) \partial d / \partial C_{u} H(t)$, which is a second-order (indirect) effect (i.e., less responsive to wealth). A large (unresponsive) health cost dampens the direct wealth effect.

The theoretical predictions with respect to health and age are ambiguous. The marginal health cost of unhealthy consumption $\pi_{d C_{u}}(t)$ is the product of the marginal cost of health investment $\pi_{I}(t)$ and the change in health due to consumption $\frac{\partial d}{\partial C_{u}} H(t)$. The marginal cost of health investment increases in wealth and decreases in health, and one would expect the wealthy and least healthy to invest more in health, a pattern that is broadly observed. ${ }^{12}$ While the marginal cost of health investment may be smaller for those in good health, the change in health due to consumption $\frac{\partial d}{\partial C_{u}} H(t)$ increases in the health stock. As a result it is unclear whether the health cost of unhealthy consumption increases or decreases in health.

Similarly, while the observed increases in medical care expenditures (health investment) toward the end of life suggest that the marginal cost of health investment $\pi_{I}(t)$ increases with age, the health cost of unhealthy consumption also depends on the relationship with age of the change in health due to unhealthy consumption $\frac{\partial d}{\partial C_{u}} H(t)$. The latter plausibly decreases with age as health declines.

In sum, the theory provides us with the following two main predictions:

1. An unexpected wealth shock leads to increased demand for healthy and moderately unhealthy consumption goods, but decreased demand for severely unhealthy goods.

2. The strength of the response to an unexpected wealth shock is smallest for the wealthy and for a high degree of unhealthiness of the consumption good. The predictions regarding health and age are ambiguous.

\subsection{Towards an empirical specification}

The first-order conditions for healthy consumption (7) and unhealthy consumption (10) guide our empirical analysis. The first-order condition for unhealthy consumption can be approximated as

$$
\frac{\partial U}{\partial C_{u}} \approx q_{A}(0) \pi_{I}(t) \frac{\partial d}{\partial C_{u}} H(t) e^{(\beta-\delta) t},
$$

if the monetary price is small compared to the health cost of unhealthy consumption, an argument made by Cutler and Lleras-Muney (2010). Under invertibility of the utility

\footnotetext{
${ }^{12}$ The marginal cost of health investment equals the ratio of the marginal value of wealth to the marginal value of health $\pi_{I}(t)=q_{A}(t) / q_{H}(t)$, and is increasing in wealth and decreasing in health under the common assumption of decreasing returns to wealth $\frac{\partial q_{A}(t)}{\partial A(t)}<0$ and to health $\frac{\partial q_{H}(t)}{\partial H(t)}<0$. Endogenous longevity complicates matters. While better health may reduce the demand for investment, at the same time better health enables life extension which may increase the return on, and therefore demand for, health investment.
} 
function, this could be approximated and linearized by

$$
\ln C_{u}=\phi_{1} \ln q_{A}(0)+\phi_{2} \ln \pi_{I}(t)+\phi_{3} \ln \frac{\partial d}{\partial C_{u}}+\phi_{4} \ln H(t)+\phi_{5}(\beta-\delta) t .
$$

The coefficients $\phi$ can be interpreted as (combinations of) the structural parameters of the model, but these are not our main interest in this study. Their estimation would require functional form assumptions, and our aim here is primarily to test the theoretical predictions. While we do not have direct measurements of all variables on the RHS of equation (15), we approximate $\ln q_{A}(0), \ln \pi_{I}(t)$ and $\ln H(t)$ by including controls for life-time full wealth (as a measure of the marginal value of initial wealth $\left.q_{A}(0)\right),{ }^{13}$ health status, and education (as an efficiency factor in the production of health). We approximate the derivative of the deterioration rate with respect to (un)healthy consumption $\frac{\partial d}{\partial C_{u}}$ with demographics such as age, sex, and environmental factors. Finally, to account for differences in the price of unhealthy consumption goods and medical services, and for region-specific policies affecting the outcomes, we include region-wave interactions.

Hence, the empirical equation to be estimated is of the form

$$
\ln C_{i, t}=\alpha+\beta_{1} \ln W_{i}+\beta_{2} \ln H_{i, t-1}+\beta_{3} \ln E_{i}+\gamma Z_{i, t-1}+\left(\tau_{t} \times \theta_{r}\right)+\varepsilon_{i, t},
$$

where $i$ denotes the individual and $t$ the wave, $C_{i, t}$ is the consumption outcome, $W_{i}$ is (initial) life-time full wealth (it can also be viewed as permanent income, which is the flow yield on the perpetuity equivalent in value to life-time full wealth; see, e.g., Heckman 1976), $H_{i, t-1}$ is lagged health status, $E_{i}$ is education (assumed to be constant over time), $Z_{i, t-1}$ covers demographic and environmental factors, $\tau_{t}$ are wave dummies, $\theta_{r}$ are regional dummies, and $\varepsilon_{i, t}$ is an error term.

Life-time full wealth $W_{i}$ is unobserved, and difficult to construct from a limited number of repeated observations for a given individual. We include individual fixed effects $\alpha_{i}$ to account for this permanent component of wealth, and exploit exogenous variation in wealth to test how variation in (life-time) wealth affects consumption decisions.

\section{$3 \quad$ Data and Methodology}

We exploit two sources of plausibly exogenous variation in wealth: lottery winnings and inheritances. ${ }^{14}$ We extract lottery winnings from the British Household Panel Survey

\footnotetext{
${ }^{13}$ The marginal value of initial wealth $q_{A}(0)=\frac{\partial}{\partial A(0)} \int_{0}^{T} U(*) e^{-\beta t} d t$, where $U(*)$ is the maximized utility function (see, e.g., Caputo, 2005). It is a function of life-time full wealth, which depends on initial wealth $A(0)$, life-time earnings, preferences, etc. and operates like permanent income in the theory of consumption (see, e.g., Heckman, 1976).

${ }^{14}$ We have also experimented with exploiting state-level variation in house prices as an instrument for individual housing wealth gains, but we could not reject a positive effect of housing wealth on the aggregate consumption of renters, casting doubts about the exogeneity of house price increases (see also Ratcliffe 2012). We also experimented with variations in stock market wealth, relying on changes in the Standard $\&$ Poors Index as in Schwandt (2011). However, our analyses could not establish an effect of increases in stock market wealth on aggregate consumption, casting doubt on its usefulness as an instrument.
} 
(BHPS) and inheritance receipt from the US Health and Retirement Study (HRS). We discuss the data sources and empirical strategies below.

\subsection{British Household Panel Survey (BHPS)}

\subsubsection{Data and descriptive statistics}

The BHPS is a multi-purpose panel survey among households in Great-Britain covering all individuals aged 15 and above in the household. The panel runs since 1991, and in 1999 samples from Scotland and Wales were added. The BHPS provides information on a wide variety of demographic, socioeconomic and health outcomes for around 15,000 individuals each year. ${ }^{15}$ We use waves 7 to 18 corresponding to the years 1997 to 2008, as relevant information on lottery winnings is not available before 1997. The total sample size is 165,488 person-year observations for 26,462 distinct individuals. Table C.1 in appendix $\mathrm{C}$ lists all variables and their units of analysis employed in this work. We discuss the dependent and independent variables in more detail below.

Dependent variables: Our first dependent variable is Food Expenditures, ${ }^{16}$ "How much do you personally spend in an average month on eating out at, or buying takeaway food from, a restaurant, pub or cafe, including school meals or meals at work?", which is not interpreted as either healthy or unhealthy but serves to verify if wealth shocks have any effect on consumption. Our measures of unhealthy consumption are Smoking, "Do you smoke cigarettes?"; Number of Cigarettes, "Approximately how many cigarettes a day do you usually smoke, including those you roll yourself?"; and Drinking Out, "How often do you go out for a drink at a pub or club?" in five categories. ${ }^{17}$ Our measure for healthy consumption is Sports, "How often do you play sport/go walking/swimming?" in the same five categories as for drinking. The Drinking Out and Sports variables are only available every other year. All monetary values are measured in natural logarithms, ${ }^{18}$ and converted to year 2005 British pounds using the Consumer Price Index (CPI). ${ }^{19,20}$

Independent variables: Accurate wealth information is only available in 2000 and 2005. We follow Banks et al. (2003) and compute Household Wealth by adding the net value of vehicles, savings accounts, investments, home and all other property, and

\footnotetext{
${ }^{15}$ For more information on the BHPS see http://www.iser.essex.ac.uk/ulsc/bhps

${ }^{16}$ Food Expenditures are only available in brackets - see Table C.1. We assign the midpoint of the relevant bracket, and for the highest bracket, which has no upper bound, we assign the lower bound.

${ }^{17}$ The categories are: "At least once a week", "At least once a month", "Several times a year", "Once a year or less", and "Never/almost never". We transformed the variables Drinking Out and Sports such that 1 represents "Never/almost never" and 5 represents "At least once a week".

${ }^{18}$ For household income and wealth, both variables to be defined below, we add 1 in order to keep observations where individuals report having zero income or wealth in our sample.

${ }^{19}$ http://www.ons.gov.uk/ons/taxonomy/index.html?nscl=Economy

${ }^{20}$ In the final year of the panel, 2008, the fraction reporting that they never engage in sports increased substantially. In a personal communication with the UK Data Archive officials acknowledged the surprising increase but could not find a satisfactory explanation. We therefore exclude the Sports variable of the last wave from our analysis.
} 
subtracting the total of mortgages and other debts. ${ }^{21}$ Lottery Winnings are based on the answer to the question "Have you personally received any payments, or payment in kind, from a win on the football pools, national lottery or other form of gambling since previous year?". If answered positively, the answer to the next question "About how much in total did you receive (was this worth)?" defines Amount Lottery Won in British pounds. Big Win is defined as amounts won of 500 British pounds or more.

Control variables: Household Income, Age, Sex, Region, Household Size, Number of Children, Level of Education, Health Status, Marital Status and Employment Status are used as control variables and are defined in Table C.1. Table 1 provides descriptive statistics by lottery winning status. Lottery winners are significantly different in many characteristics from non-winners. They are slightly younger, more often male, married and college educated, but with fewer children, and located in different regions of the United Kingdom (they are more likely to live in the North, South and East and less likely to live in Wales and Northern-Ireland). In line with the findings by Imbens et al. (2001) among a sample of lottery winners in Massachusetts and Apouey and Clark (2010) using the BHPS, but in contrast to a US survey by Clotfelter and Cook (1989), lottery winners have slightly higher household income and wealth, and are more often employed.

\subsubsection{BHPS Methodology}

Even though winning the lottery likely represents an unanticipated shock to wealth (Imbens et al. 2001; Gardner and Oswald 2007; Apouey and Clark 2010), it is not randomly distributed across the population - not everyone plays the lottery, and lottery winners differ in various characteristics from non-winners (see Table 1). Moreover, the group of non-winners includes individuals that did not play the lottery, and individuals that did play but did not win. These too may be very different groups. A limitation of the BHPS is that we cannot distinguish between non-winners who played and non-players. For these reasons, using a simple regression of the dependent variable on an indicator of winning the lottery, we cannot estimate the causal effect of winning the lottery on the outcome. Including a battery of control variables may improve the inference, but is unlikely to fully overcome the endogeneity of lottery winnings. We use three different strategies to overcome the endogeneity issue.

First specification: FE Lottery Won Our first approach is to include an individual-specific fixed effect to account for the fact that lottery winners are intrinsically different from non-winners. The fixed effect controls for all time-invariant personal characteristics likely to influence both lottery play and health behaviors, such as life-time full wealth (or permanent income), education, risk aversion, cognitive and non-cognitive abilities, and time preference. A parsimonious version of equation (16), including an individual specific fixed effect, can be written as

$$
\ln C_{i, t}=\alpha_{i}+\beta I_{i, t}+\gamma^{\prime} X_{i, t-1}+\left(\tau_{t} \times \theta_{r}\right)+\varepsilon_{i, t},
$$

\footnotetext{
${ }^{21}$ These wealth and debt measures are available in unfolding brackets. We assign the midpoint of the relevant bracket, and for the highest bracket, which has no upper bound, we assign the lower bound.
} 
where $C_{i, t}$ is the outcome measure for individual $i$ at time $t, \alpha_{i}$ represents the individual-specific fixed effect, $I_{i, t}$ is a binary indicator of whether one won the lottery or not, $X_{i, t-1}$ is a matrix of plausibly exogenous control variables including lagged health, and $\left(\tau_{t} \times \theta_{r}\right)$ are the interactions between time dummies and region dummies capturing regional differences over time regarding the business cycle, inflation, monetary prices, excise taxes, and other changes affecting the outcome and lottery play that differ between regions over time.

Second specification: FE Big Lottery Won Our second approach is based on Imbens et al. (2001) and distinguishes between "small" and "big" lottery winnings. This offers two advantages over the first specification. First, below a certain threshold, lottery winnings are unlikely to influence behavior and including them will attenuate the coefficient estimates. Second, since individuals who win small amounts plausibly share characteristics with individuals who win big amounts, they can act as a natural control group for the big winners. This approach involves two fundamental assumptions: (1) conditional on winning the lottery, the amount won is unrelated to personal characteristics, and (2) small lottery winnings are too small to materially affect wealth and consumption behavior. Under these two assumptions, and controlling for small lottery winnings, big lottery winnings represent the effect of a wealth shock. The drawback of this approach is that one needs to determine a threshold above which lottery winnings are considered big, which is essentially arbitrary.

In order to make this process least arbitrary we tested these two assumptions for different threshold levels. On the basis of these analyses, ${ }^{22}$ thresholds at 250, 500, and 1,000 British pounds were deemed most appropriate. Using these thresholds, statistically significant differences between small and big winners are fewest, and winning a big amount has a statistically significant effect on both wealth ${ }^{23}$ and food expenditures. Table 1 presents the differences in the covariates' means across small and big lottery winners. For reasons of space we only present the results for the threshold at 500 British pounds (results are very similar for the 250 and 1,000 British pounds thresholds). Although

\footnotetext{
${ }^{22}$ We placed the threshold at the median win of 32 , and at 50, 100, 250, 500, 1,000, 5,000, and 10,000 British pounds, and, following Imbens et al. (2001), performed t-tests on the difference in the means of independent and control variables across small and big lottery winners for all threshold levels. In case the amount won is random, one would expect no differences in observable characteristics across small and big lottery winners. If the t-tests cannot reject that the means of the observable characteristics are similar, this is taken as evidence that winning a big or small amount is essentially random. We further investigated the coefficients of big lottery winnings (as defined by the different thresholds) on the log of 2000 and 2005 household wealth and food expenditures, to test whether big lottery winnings had an additional effect - over and above small winnings - on wealth and on food expenditures (as a proxy for aggregate consumption). Although these tests do not validate the assumption that small winnings do not materially affect wealth and consumption behavior, they do confirm that big lottery winners respond more to a lottery win than do small lottery winners. Results of these analyses are available upon request.

${ }^{23}$ We cannot use the impact of lottery winnings on wealth as a viable first stage in an Instrumental Variables (IV) strategy. Since part of the money won in the lottery will be spent on consumption, it will not be included in reported wealth in the survey. This would lead to underestimating the effect of the lottery win on wealth, and hence overestimating any impact of wealth on the consumption outcomes.
} 
differences in average characteristics between small and big winners are smaller than between non-winners and lottery winners (see also Table 1), important differences remain, e.g., males are overrepresented in the "Big Win" group, and this group is less educated, less often married, and more often self-employed. Plausibly this residual heterogeneity stems from the fact that we do not observe the number of lottery tickets bought, which could be related to individual characteristics such as sex and income. To account for this residual heterogeneity within the group of lottery winners, we add an individual-specific fixed effect. The corresponding equation, our second specification to be estimated, can be summarized as

$$
\ln C_{i, t}=\alpha_{i}+\beta_{1} I_{i, t}+\beta_{2} I\left[A_{i, t}>c\right]+\gamma^{\prime} X_{i, t-1}+\left(\tau_{t} \times \theta_{r}\right)+\varepsilon_{i, t},
$$

where $A_{i, t}$ denotes the amount won, $c$ represents the threshold for big lottery winnings, here taken as 500 British pounds, $I[\cdot]$ is the indicator function ( 1 when true, 0 if false), and $\beta_{2}$ measures the effect of a wealth shock (big lottery win) on the relevant outcome.

Third specification: FE Log Amount Lottery Won A related, and final, approach is to substitute the logarithm of the amount won $A_{i, t}$ directly in the specification. The notion is that larger winnings represent larger increases in wealth and may affect the outcomes stronger. The approach is again based on the assumption that conditional on winning the lottery, whether you win a big or small amount is random. An advantage of this approach is that it does not require setting an arbitrary threshold. This approach is implemented by Apouey and Clark (2010) by restricting to lottery winners but not including individual fixed effects. As argued before, since we do not observe the number of lottery tickets bought, those who won large amounts could be intrinsically different from those who won small amounts. Therefore, we extend the specification of Apouey and Clark (2010) by including individual-specific fixed effects, which defines our third specification:

$$
\ln C_{i, t}=\alpha_{i}+\beta \ln A_{i, t}+\gamma^{\prime} X_{i, t-1}+\left(\tau_{t} \times \theta_{r}\right)+\varepsilon_{i, t} .
$$

\subsection{Health and Retirement Study (HRS)}

\subsubsection{Data and descriptive statistics}

To exploit exogenous variation in wealth deriving from inheritances we use the US Health and Retirement Study (HRS) for the years 1992-2010. For most of the variables we use the RAND version of the HRS, which is a user-friendly, harmonized version of the data. The information regarding inheritance receipt and expectations, the number of cigarettes smoked per day, and food expenditures are taken from the original HRS files. The initial HRS cohort consists of around 13,500 individuals born between 1931 and 1941. It has been appended by additional cohorts of different birth years. The total sample size consists of 153,024 person-year observations for 27,900 distinct individuals. Table C.2 lists all variables and their units of analysis. We discuss the dependent and independent variables in more detail below. 
Dependent variables: Our first dependent variable in the HRS is Food Expenditures, ${ }^{24}$ which again is not interpreted as either healthy or unhealthy but serves to verify if wealth shocks have an effect on overall consumption. Measures of unhealthy consumption are Smoking, "Do you smoke cigarettes now?"; Number of Cigarettes, ${ }^{25}$ "About how many cigarettes or packs do you usually smoke in a day now?"; Drinking, "Do you ever drink any alcoholic beverages, such as beer, wine, or liquor?"; Number of Drinks, which is the product of the answers to the questions "In the last three months, on average, how many days per week have you had any alcohol to drink?" and "In the last three months, on the days you drink, about how many drinks do you have?" (this definition is also used by Kim and Ruhm 2012); and Heavy Drinking, a binary indicator of whether the individual drinks 3 or more glasses on an occasion when drinking (this definition is also used by, e.g., Cutler and Glaeser 2005; Arcidiacono et al. 2007). Our measure of healthy consumption is Light Physical Activity, "How often do you take part in sports or activities that are mildly energetic, such as vacuuming, laundry, home repairs?", measured in five categories; and a measure of health investment is Out-of-Pocket Medical Expenditures, a self-reported estimate of expenditures since the previous interview on four groups of services: hospital/nursing, doctor/outpatient/dental, prescription drugs, and home health care/special facilities.

For both the number of cigarettes smoked per day and for out-of-pocket medical expenditures, the question wording changed considerably from wave 1994 to 1996 . Therefore, in the analyses of cigarettes per day and out-of-pocket medical expenditures we restrict our analysis to wave 1996 and beyond. Frequency of drinking is only available from 1996 on, and food expenditures are only available from 2000 on. Light physical activity is used since 2004 due to a major change in the question wording. All monetary values are measured in natural logarithms, ${ }^{26}$ and converted to 2005 US dollars using the Consumer Price Index (CPI). ${ }^{27}$

Independent variables: Household Wealth is defined as the sum of all wealth components less all debt. ${ }^{28}$ Information on Inheritance receipt is obtained from the question "In the past two years, have you (or your partner) received money or property in

\footnotetext{
${ }^{24}$ Food Expenditures are the sum of the answers to three questions pertaining to food expenses: (1) "About how much do you (and other family members living there) spend on food that you use at home in an average week?", (2) "About how much do you spend in an average week on food delivered to the door?", and (3) "About how much do you spend eating out in a typical week, not counting meals at work or at school?"

${ }^{25}$ The number of cigarettes per day is recorded in either single cigarettes or packs. We assumed that a pack consists of 20 cigarettes to convert packs into cigarettes.

${ }^{26}$ For out-of-pocket medical expenditures, food expenditures, household income and household wealth we add 1 in order to keep observations where respondents report zero value.

${ }^{27}$ http://www.bls.gov/cpi/

${ }^{28}$ Wealth components include the net values of (i) primary residence, (ii) real estate other than primary residence, (iii) vehicles, (iv) businesses, (v) Individual Retirement Accounts (IRAs) and Keogh accounts, (vi) stocks, mutual funds, and investment trusts, (vii) Certificate of Deposits (CDs), government savings bonds, and T-bills, (viii) bonds and bond funds, and (ix) all other savings. Debt components include the net value of (i) all mortgages on the primary residence, (ii) other home loans, and (iii) all other debt.
} 
the form of an inheritance, a trust fund, or an insurance settlement?", where we disregard trust funds and insurance settlements. If answered affirmative, the respondents are asked "About how much did you receive from the inheritance?". The answer to this question defines Amount Inherited. Individuals not providing exact amounts were requested to answer whether the value was less than, about, or more than 50,000 US dollars, which we converted to $17,276,50,000$, and 186,509 US dollars, respectively, given the sample averages in those categories (taken from Kim and Ruhm 2012). Big Inheritance is defined as amounts received of 10,000 US dollars or more. We drop individuals who report having received an inheritance before the first wave (1992), as we don't know the exact timing of the receipt, and this could bias the estimates.

Control variables: Household Income, Age, Sex, Race, Census Region, Household Size, Number of Children, Years of Education, Health Status, Marital Status, Employment Status, Ever Smoked, and Health Insurance are used as control variables and are defined in Table C.2. Additionally we include controls for whether Mother Died, Father Died, Mother in Law Died, or Father in Law Died, and whether the individual got Widowed.

Table 2 presents the averages of the control variables by inheritance receipt status. Inheritance recipients are statistically significantly different in nearly every single domain from non-recipients. White, wealthy, working, higher educated, and high income individuals are more likely to receive an inheritance. Further, inheritance recipients are slightly younger, more often married, and have fewer children. As one would expect, the fraction for which a parent or parent in law died is considerably higher in the inheritance recipients group. When comparing small with big inheritance recipients, differences become smaller, but are still substantial and statistically significant in many cases. Apart from being slightly older, big inheritance recipients are in better health, are higher educated, earn more income and have substantially more wealth.

\subsubsection{HRS Methodology}

The empirical strategy exploiting inheritances is almost identical to the one for lottery winnings. Our Fourth specification: FE Inheritance is a fixed effects estimation replacing lottery winnings by inheritance receipt in equation (17) (section 3.1.2). Our Fifth specification: FE Big Win is the equivalent of equation (18) in section 3.1.2 using a cut-off of 10,000 US dollars following Kim and Ruhm (2012), and our Sixth specification: FE Log Amount Inherited consists of replacing the amount won in the lottery by the amount received through an inheritance in equation (19) (section 3.1.2).

The receipt of an inheritance has been shown to represent useful and important variation in wealth (see Meer et al. 2003; Michaud and Van Soest 2008; Kim and Ruhm 2012), although questions have been raised regarding its exogeneity and whether inheritances are unanticipated. We seek to address the potential endogeneity of the receipt and size of an inheritance by including individual fixed effects and control variables in our specifications. To gauge the severity of the anticipation effect, we followed Goodstein (2008) and experimented with controlling for the lagged subjective probability 
of receiving an inheritance, obtained from information in the HRS on expectations about inheritances available in waves 1994 to $2006 .{ }^{29}$ The results were very similar to our baseline specifications (and are available upon request). Further, anticipation of inheritances would only lead to underestimating any wealth effect on consumption, inheritance expectations are available only for the period 1994 to 2006, and are subject to large item non-response. For these reasons, we do not use expectation information in our baseline specifications. Finally, the receipt of an inheritance may be associated with a bereavement effect due to the loss of a beloved one that may independently affect health behavior. We therefore control for the death of family members in our specifications (Brown et al. 2010). ${ }^{30}$

\section{Results}

In section 4.1 we present results for the BHPS and in section 4.2 for the HRS.

\subsection{The effect of lottery winnings}

We estimate the three fixed effects specifications (17), (18) and (19) for the full BHPS sample to verify theoretical prediction 1 of section 2.3, and estimate the same regressions for subgroups defined by (i) an imputed wealth measure and health status, and (ii) age, to verify theoretical prediction 2 of section 2.3 .

The analyses include the following control variables: the first lag of log household income, age, age-squared, ${ }^{31}$ first lag of region dummies (19 regions), first lag of household size, first lag of the number of children, first lag of health status (five categories), first lag of marital status (seven categories), first lag of employment status (ten categories), and interactions between time dummies and region dummies capturing regional differences over time.

We estimate the impact of lottery winnings on smoking separately for those who smoked in the previous wave and for those who did not, as the decision to quit or initiate smoking are very different (e.g., Gilman et al. 2003). For the number of cigarettes consumed, we restrict the analyses to those who smoked in the last wave. In all models we use robust standard errors clustered at the individual level.

Full sample Lottery winnings are fairly common, ranging from 7 to 19 percent of the sample in each year. Over the course of the panel 7,113, or 27 percent, out of a total of 26,462 distinct individuals won the lottery at least once. The first column of Table 3 provides descriptive statistics of the sample. The average of the log amount corresponds

\footnotetext{
${ }^{29}$ We include a dummy in the regressions for observations where subjective probabilities of receiving an inheritance are missing.

${ }^{30} 47.68$ percent of inheritances comes from parents, 22.17 percent from parents in law, 2.31 percent from siblings, 21.98 percent from other relatives (grandparents, aunts/uncles), 1.55 percent from (ex-)spouse, and 4.31 percent from other sources.

${ }^{31}$ All results are robust to including a quartic polynomial in age to allow for a more flexible relationship between the outcomes and age.
} 
to around 40 British pounds, ${ }^{32}$ which is less than one percent of total household wealth. Between 3 and 8 percent of lottery winners in any year win an amount over 500 British pounds. The average of the log amount won in this group corresponds to 1,500 British pounds, representing two percent of household wealth and six percent of annual household income.

Table 4 presents the results of estimating the models FE Lottery Won (17), FE Big Lottery Win (18), and FE Log Amount Won (19). Panel 1 shows a positive effect of lottery winnings on food expenditures that is statistically significant in two out of three models. The lack of an effect in the first specification (FE Lottery Won) may be due to the fact that many lottery winnings are not large enough to affect consumption decisions, and their inclusion attenuates the estimate. For this reason our preferred specifications are FE Big Lottery Won and FE Log Amount Won. The size of the coefficient in the FE Big Lottery Won specification is 0.096, suggesting that food expenditures increase by around ten percent following a big lottery win. The baseline amount spent on eating out is around 25 British pounds (exp(3.20); see Table 3), suggesting that individuals spend 2.5 British pounds more per month on eating out after a win of 1,500 British pounds, on average. ${ }^{33}$ The effect on food expenditures builds confidence that (big) lottery winnings represent unanticipated and important variation in wealth.

The top panel of Table 4 shows no effect on either smoking ${ }^{34}$ or, conditional on smoking in the previous wave, the number of cigarettes smoked. Using the FE Big Lottery Won specification, we can rule out prevalence changes larger than 1.4 percentage points (or 5.2 percent [at the 5 percent level]), and prevalence changes in the number of cigarettes smoked larger than 16.8 percent (or more than 1.8 cigarettes [at the 5 percent level]; see also Table 3). This is in contrast to the results presented by Apouey and Clark (2010), which we replicated (see Table C.3 in the appendix). By including individual fixed effects we control for time-invariant unobserved differential characteristics that render the effect of winning the lottery on smoking and the number of cigarettes insignificant. This suggests that the OLS results presented by Apouey and Clark (2010) may not be reflecting a causal impact of wealth on the outcomes, but be due to differential characteristics of those that win larger amounts compared to those that win smaller amounts. The difference in results could also reflect larger standard errors in our fixed effects specification, but comparing Table C.3 and Table 4 suggests it is rather smaller point estimates than smaller standard errors that induce the loss of significance.

\footnotetext{
${ }^{32}$ We compute the average amount won as the exponent of the mean log amount won, since the log amount is used in our empirical specifications, and the distribution of lottery winnings is heavily skewed, with very large amounts increasing the raw average substantially. For comparison, the average amount won is about 250 and the median amount is 32 British pounds.

${ }^{33}$ It is not straightforward to arrive at a comparable interpretation for the FE Log Amount Lottery Won specification, where we have $\frac{\partial y}{y}=\beta \frac{\partial x}{x}$ but no good measures of $x$. For this reason we focus on the FE Big Lottery Won specification to quantify effect sizes.

${ }^{34} \mathrm{~A}$ positive (negative) coefficient of a lottery win on the prevalence of smoking, conditional on smoking in the previous wave, implies that lottery winners are more (less) likely to continue smoking than those not winning the lottery, conditional on smoking in the previous wave.
} 
We find strong and robust evidence that lottery winnings increase the frequency of drinking out in a pub or club. The effect is statistically significant in all models estimated. To get an idea of the size of this effect, we used the probability of drinking out at least once a month as dependent variable in our three specifications (not shown). In our FE Big Lottery Won specification the coefficient is 0.0466 and is statistically significant at the five percent level. Hence, upon winning an amount of 1,500 British Pounds in the lottery, the probability of drinking out at least once a month increases by around five percentage points, or ten percent given a baseline prevalence of around 50 percent. The frequency of engaging in sports shows a positive response to lottery winnings in two out of three models, but the effect size is rather small. Again, to get an idea of the size of this effect, we used the probability of engaging in sports at least once a month in our three specifications (also not shown). Winning the lottery increases the probability of engaging in sports at least once a month by 1.76 percentage points, or 2.60 percent.

Subgroup analyses We analyze the responses in four subgroups: (a) most healthy most wealthy, (b) most healthy least wealthy, (c) least healthy most wealthy and (d) least healthy least wealthy.

According to our theory, responses to a change in wealth are a function of life-time full wealth $W_{i}$ (see equation 16). Ideally we would like to split the sample on the basis of this measure. Unfortunately, life-time full wealth is difficult to construct since household wealth is only available in two waves and even then it is often missing. For this reason we determine the age-wave specific median level of wealth, obtained from an imputed measure of household wealth, to divide the sample into wealth subgroups. We obtain Imputed Household Wealth as follows. In the years 2000 and 2005, where we observe actual household wealth, we regress it on the set of control variables from Table C.1, particularly household income, health, age, age-squared, and the level of education. We use this model to predict household wealth for all individuals and years. ${ }^{35}$

Ideally we would also like to use the age-wave specific median (or average) health to divide the sample by health status, but since the self-reported health measure is only available in five categories, this is not feasible. We therefore simply split the sample according to whether one's initial health (at panel entrance) is "Excellent" or "Good" on the one hand, or "Fair", "Poor" or "Very Poor" on the other. Then, within those subsamples we stratify according to whether the initial imputed wealth (at panel entrance) is above or below the age-wave-specific median imputed wealth. ${ }^{36}$ We use imputed wealth and self-reported health at first observation since these measures are not contaminated by possible lottery winnings during our observation period.

The top half of Table 3 shows that a lottery win represents less than one percent of total household wealth for all subgroups. In contrast, a "Big Win" of over 500 British

\footnotetext{
${ }^{35}$ Our imputed measure of wealth behaves nicely, gradually increasing over the years of the panel, and we believe it contains substantially more information than simply using education as an indicator of lifetime wealth. As a robustness check we also used educational attainment as a measure of full wealth to stratify the sample. Results were very similar, cf. the robustness checks in section 4.3.

${ }^{36}$ We use 5 -year age brackets from $15-19,20-24, \ldots 75-79$, and 80 and higher, to avoid small cell sizes.
} 
pounds represents, respectively, 5 and 28 percent of household wealth, for the most healthy least wealthy and the least healthy most wealthy. For wealthier individuals the wealth shock is around one percent of household wealth.

Panels two to five of Table 4 show how the different groups respond to exogenous variation in wealth in the form of lottery wins. The results suggest that larger lottery winnings (wins of over 500 British pounds [FE Big Lottery Won], or a larger monetary amount [FE Log Amount Lottery Won]) increase food expenditures in all groups, although point estimates are not always statistically significant. Consistent with the results for the full sample, for none of the wealth-health subgroups we observe an effect on smoking or on the number of cigarettes consumed. The point estimates for drinking out are positive in all subgroups, although they are not always statistically significant.

We also stratify the sample by age, defining two groups: (i) those who are still below age 50 in the last wave of the panel (year 2008), and (ii) those who are above age 50 in 2008.For both age groups a "Big Win" represents about 2 percent of household wealth (see Table 3). Panels six and seven of Table 4 present the results for the effect of lottery wins by age groups. Both younger and older individuals show some response in food expenditures. Consistent with the results from the full sample, none of the two subgroups respond to a lottery win by changes in the prevalence of smoking or, when smoking, in the number of cigarettes smoked. The effects on drinking out and sports are larger and more pronounced among the elderly.

\subsection{The effect of inheritances}

We first estimate the three specifications (17), (18), and (19) for the full HRS sample to verify theoretical prediction 1 of section 2.3 using inheritances. Then we estimate the three specifications for subgroups defined by wealth and health to verify theoretical prediction 2 of section 2.3. Because the age range is much smaller in the HRS than in the BHPS we do not investigate subgroups by age. We estimate the impact of inheritance receipt on smoking separately for those who smoked in the previous wave and those who did not smoke. For cigarette consumption, we restrict to those that smoked in the last wave, and we restrict to those that drank in the previous wave to estimate the effect on the number of drinks and the indicator for heavy drinking. In all models we use robust standard errors clustered at the household level, as the sample includes both respondents and their spouses.

The analyses include the following control variables: the first lag of log household wealth, the first lag of log household income, age, age-squared, first lag of census region dummies (five regions), first lag of household size, first lag of number of children, first lag of health status (five categories), first lag of marital status (eight categories), first lag of employment status (binary), first lag of health insurance, whether mother, father, mother in law or father in law died since the last wave, whether became widowed since last wave, and interactions between time dummies and region dummies capturing regional differences over time. 
Full sample Between 2.7 and 6.9 percent of the sample received an inheritance over the waves. Table 3 shows that in contrast to lottery winnings, the mean of the log of inheritance is substantial: corresponding to around 40,000 US dollars, ${ }^{37}$ or 12 percent of current wealth. Around 80 percent of all inheritances can be considered "big": between 1.9 and 5.9 percent of the sample received an inheritance of more than 10,000 US dollars over the waves.

Panel 1 of Table 5 presents the results of estimating models FE Inheritance (17), FE Big Inheritance (18), and FE Log Amount Inherited (19) using inheritance receipts rather than lottery winnings, and using the HRS rather than the BHPS. The first line presents evidence that the receipt of an inheritance increases food expenditures. Individuals spend on average about 100 US dollars on food per week $(\exp (4.64)$; see Table 3$)$, and the receipt of an inheritance increases this by 4.9 percent (see under FE Inheritance in Panel 1 of Table 5), suggesting that receipt on an inheritance of 40,000 US dollars on average increases food expenditures per week by around 5 US dollars (or about 260 US dollars per year).

Yet, using the FE Big Inheritance specification as in Kim and Ruhm $(2012)^{38}$ we find no evidence of an increase in food expenditures. This may be because the working hypothesis that inheritances under 10,000 US dollars are small enough not to impact behavior is invalid, and this would lead to underestimation of effect sizes. There appears to be some evidence of this as fewer statistically significant effects are found for the FE Big Inheritance specification as for the other two, with the exception of a significant decrease in light physical activity. Moving the cut-off down decreases the number of small inheritances drastically, and point estimates and their statistical significance are sensitive to the chosen cut-off (results are available upon request). In short, we find this specification problematic in the case of inheritances and do not further employ it in the subsequent subgroup analyses.

A sudden wealth increase in the form of an inheritance receipt increases the prevalence of smoking by around one percentage point (see under FE Inheritance in Panel 1 of Table 5), or 6.0 percent (see Table 3). ${ }^{39}$ Although not statistically significant, the point estimates are larger for those who previously smoked, suggesting that what drives the effect on smoking prevalence is smokers not quitting rather than non-smokers initiating.

\footnotetext{
${ }^{37}$ We compute the average as the exponent of the mean log amount received as the log amount is used in the empirical specifications, and the distribution of inheritances is heavily skewed. The mean inheritance is over 300,000 US dollars, and the median is around 37,000 US dollars.

${ }^{38} \mathrm{Kim}$ and Ruhm (2012) define "Big Inheritance" as an indicator whether the cumulative amount received by the current survey wave is greater than 10,000 US dollars. Using cumulative amounts seems appropriate for an outcome such as health, the focus of their paper, for which wealth changes are likely to have a delayed affect. We focus on instantaneous responses to inheritance receipt, which seems more appropriate for our consumption outcomes. Additionally, using our specification we can identify the exact timing of the impact, whereas employing cumulative amounts treats inheritances received 18 years ago and inheritances received this year in the same way.

${ }^{39}$ As before, it is not as straightforward to arrive at a comparable interpretation for the FE Log Amount Inherited specification, where we have $\frac{\partial y}{y}=\beta \frac{\partial x}{x}$ but no good measures of $x$. For this reason we focus on the FE Inheritance specification to quantify effect sizes.
} 
On the intensive margin, smokers increase the number of cigarettes they smoke per day by around ten percent on average. A sample average of $8.8(\exp (2.18))$ cigarettes per day among smokers suggests that inheritance recipients receiving an amount of 40,000 US dollars, or 12 percent of household wealth, on average, smoke about 0.9 cigarettes more per day.

The prevalence of drinking also increases following the receipt of an inheritance by 1.37 percentage points, or 2.76 percent. There is no evidence of a change in the number of drinks consumed per week or in the prevalence of heavy drinking. Light physical activity and out-of-pocket expenditures on medical care are not affected by the receipt of an inheritance (although there is weak evidence that out-of-pocket expenditures on medical care increase with the size of the inheritance).

Our findings challenge those of Kim and Ruhm (2012) who reported an effect of a big inheritance receipt on both the prevalence and intensity of drinking, but not on smoking or on the number of cigarettes smoked. This suggests that the findings of Kim and Ruhm (2012) may be driven by unobserved heterogeneity across inheritance recipients below and above the threshold of 10,000 US dollars they employed.

Subgroup analyses In the subgroup analyses, we stratify the sample by initial wealth and initial self-reported health similar to lottery winners (panels two to five of Table 5). We define four groups of roughly similar size. We first divide the sample on the basis of initial self-reported health, where "Excellent" and "Very Good" health form the "Most Healthy" group, and "Good", "Fair" or "Poor" health form the "Least Healthy" group. Then within those groups we stratify by wealth, where the "Most Wealthy" group is defined as individuals whose wealth at first observation is greater than the age-wave-specific median wealth. ${ }^{40}$ The remainder constitutes the "Least Wealthy" group. The bottom half of Table 3 shows that for all subgroups an inheritance represents a substantial wealth shock. For the most healthy most wealthy, an inheritance represents eight percent of household wealth on average, and this increases to 40 percent for the least healthy least wealthy.

Table 5 shows the effect of inheritance receipt among the same four subgroups. The most striking observation is that virtually all results seem to be driven by the healthier part of the population (panels 2 and 3). An exception is light physical activity where the most healthy and most wealthy (panel 2) decrease and the least healthy and most wealthy (panel 4) increase their activity. The fact that virtually no response is seen among the least healthy shows that, even though the relative size of the wealth shock is larger among the least healthy, the most healthy respond more to a change in wealth. This suggests that the direct wealth effect alone cannot explain the observed behavioral responses, and that health costs are important and larger for unhealthy individuals.

Within the healthy group of individuals, the prevalence of smoking and drinking increases upon receipt of an inheritance, with larger effect sizes for the least wealthy compared to the most wealthy: the most healthy most wealthy increase smoking by

\footnotetext{
${ }^{40}$ We use five-year age brackets: below $50,50-54, \ldots, 80-84$, and above 85 .
} 
around 1.1 percentage point (or 10 percent) and drinking by 1.8 percentage points (or 2.7 percent), while the most healthy least wealthy increase their prevalence of smoking by 2.3 percentage points (or 13 percent) and drinking by 2.9 percentage points (or 5.6 percent).

Interestingly, for the most healthy and least wealthy a positive effect is found in the number of cigarettes consumed but not for other subgroups. This finding is in line with the theoretical prediction (cf. prediction 2 in section 2.3) that the response to a wealth shock is stronger for individuals with low health costs, i.e. for the least wealthy. Given the average number of cigarettes smoked per day in this group is $8.9(\exp (2.19))$, the point estimate suggests an increase of 24.3 percent, or around 2.2 cigarettes per day.

\subsection{Robustness Checks}

In performing the analyses we ran a battery of robustness checks, results of which are available upon request. First, we investigated differential responses by gender, and while the effects on females are typically slightly larger than for males, we couldn't reject the null hypothesis that effects are similar across genders. We therefore only present results for the full sample. Second, while the three models (17), (18) and (19) are specified in linear form, we also estimated logit models for the binary indicators, and negative-binomial count models for the variables concerning the number of cigarettes and the number of drinks. The results were very similar.

We experimented with using lottery winnings and inheritances one period lagged to allow for some time delay in the response. This exercise produced similar results for lottery winnings in the BHPS, while the point estimates using inheritances in the HRS were much smaller and mostly insignificant. This suggests that the largest effect of inheritances in the elderly HRS population is immediate, and that most of the windfall gains are spend quickly. This interpretation is corroborated by the fact that two waves after the receipt of an inheritance the wealth of inheritance recipients is barely higher than for non-inheritance recipients. Further, there are no significant differences in food expenditures between recipients and non-recipients one wave after receipt of an inheritance.

Relative rather than absolute changes in wealth may matter in consumption decisions. We experimented with replacing the logarithm of the amount won or inheritance received $A_{i, t}$ by the logarithm of the ratio of the amount won or received over total current household income (BHPS) or total current household wealth (HRS). Results were very similar.

We have used a static selection procedure to define subgroups by initial health and initial wealth. This has the advantage that the individuals selected into one of the four subgroups remain in that subgroup over the course of the panel study. Alternatively, one might consider a dynamic selection procedure in which one stratifies individuals dynamically on the basis of the previous' wave wealth and health. This has the advantage that the information is more up-to-date, but we no longer follow the same subgroup of individuals. We also used this dynamic selection procedure and found that differences 
were minimal.

In addition, we replaced our imputed wealth measure by education for the purpose of defining subgroups of lifetime full wealth, distinguishing in the BHPS between three education levels on the basis of the OECD International Classification (ISCED - OECD 1996). "Lower Educated" are those with less than secondary school (levels 8-12 in Table C.1), "Intermediate Educated" refer to those that completed secondary school (levels 6-7 in Table C.1), and "Higher Educated" refer to those with at least some post-secondary schooling (levels 1-5 in Table C.1). For the HRS we also distinguished between three educational levels on the basis of years of education: those with less than 12 years of education (29 percent of the sample), exactly 12 years of education (33 percent), and more than 12 years of education (38 percent). Results were very similar.

As in most panels, there is considerable attrition in the BHPS and the HRS: 30 and 36 percent of the sample, respectively, is lost by the final wave. We repeated the analyses using inverse probability weights to correct for sample attrition (Jones et al. 2006), and find very similar point estimates. Hence attrition bias does not alter any of our main conclusions. ${ }^{41}$

\section{Discussion}

This paper presents a theory of health behavior, in which the marginal cost of unhealthy consumption consists not only of the direct monetary outlays, as in standard life cycle models, but also of a health cost (value of health lost). As a result, wealth has two competing effects: (i) a direct wealth effect increasing demand for unhealthy consumption (wealth allows individuals to purchase more [unhealthy] consumption goods), and (ii) an indirect health cost effect decreasing the demand for unhealthy consumption goods (the health cost is higher for those who invest more in health, i.e. for wealthy individuals). Which of the two effects dominates is theoretically ambiguous, but, according to our theory, the indirect health cost effect is larger for the wealthy and for severely unhealthy goods.

A first prediction of the theory is therefore that a wealth shock leads to increased demand for healthy and moderately unhealthy consumption goods, but decreased demand for severely unhealthy goods. This may provide an economic rationale for why wealthier

\footnotetext{
${ }^{41}$ We use probit regressions to predict the probability of remaining in the sample as a function of the following initial wave explanatory variables: household income, age, age squared, sex, household size, number of children, household income, education, health status, region, employment status, and marital status. In the HRS models we additionally included race, health insurance, and whether father died, mother died, father in law died or mother in law died and an indicator for being widowed. We use the inverse of these predicted probabilities to weight each individual in the analyses of interest. BHPS results show very similar point estimates, and while the HRS results also indicate very similar point estimates, the effect on food expenditures is not statistically significant using the attrition weights, and the effect on out-of-pocket expenditures on medical care is not significant in the FE Log Amount Inherited specification. In contrast, the effect on smoking for non-smokers is statistically significant using the attrition weights in the FE Log Amount Inherited specification.
} 
individuals are more likely to drink moderately, but less likely to smoke and drink heavily (Cutler and Lleras-Muney 2011). A second prediction is that the strength of the response to an unexpected wealth shock is smallest for the wealthy and for a high degree of unhealthiness of the consumption good, while predictions regarding health and age are ambiguous.

We employ lottery winnings and inheritances as plausible exogenous variation in wealth to test the theory's predictions. Tables 6 and 7 provide a high-level overview of the key findings (distilled from Tables 4 and 5). A + indicates a positive response and a - indicates a negative response. ${ }^{42}$ Table 6 summarizes the results for the full BHPS and HRS samples and serves to test prediction 1. We find strong and robust evidence that wealth shocks increase the prevalence of drinking alcohol, but the number of drinks and heavy drinking are not affected. This suggests that it is mostly modest, occasional drinking that increases following a wealth shock. Apparently, for moderate drinking the direct wealth effect dominates the indirect health cost effect, which is in line with what the theory predicts (cf. hypothesis 1 that a wealth increase leads to increased demand for moderately unhealthy behaviors). Heavy drinking is plausibly more detrimental to health than drinking moderately and the absence of an effect on heavy drinking would be consistent with the theoretical prediction that in such cases the health cost effect dampens the direct wealth effect.

While a lottery win in the BHPS does not, inheritance receipt in the HRS does increase the prevalence of smoking and the number of cigarettes smoked. These results are however not necessarily inconsistent with one another. In the HRS we estimate a 1 percentage point or 6.0 percent increase in the prevalence of smoking and a 0.9 increase in the number of cigarettes smoked per day. In the BHPS results were insignificant, and we can rule out an increase by more than 1.4 percentage points or 5.2 percent in the prevalence of smoking, and an increase by more than 1.8 cigarettes per day (all at the 5 percent level). Thus the absence of an effect in the BHPS does not rule out the effect sizes estimated in the HRS. In addition there are substantial differences in age and in the size of the wealth shocks between the BHPS and the HRS. Inheritances in the HRS represent a substantial amount of money (the mean log amount received corresponds to around 40,000 US dollars), whereas the amount won in the lottery is much smaller (mean log amount corresponding to 40 British pounds, 1,500 Pounds among "Big Winners"). These differences in the size of the wealth shock could simply render the effects on smoking insignificant in the BHPS sample. $^{43}$ A priori, we would classify smoking as very unhealthy. In light of the theory

\footnotetext{
${ }^{42}$ Effects are included if at least one effect size is recorded at a p-value of $<0.05$ or at a p-value of at least $<0.1$ in two specifications. Note, that one has to be careful in comparing results from the BHPS directly with those for the HRS as the wealth shocks employed, the demographics, countries and institutions and panel questionnaires are different. Especially for the concepts "Exercise" and "Drinking" the BHPS and HRS do not measure the same thing. While the BHPS question asks about engaging in sports and drinking out, the HRS questions are broader and ask about any light physical activity and drinking in general.

${ }^{43}$ When restricting to lottery winners who won amounts over 1,000 or 2,500 British pounds the point estimates increase slightly, but never reach statistical significance. It seems that the number of individuals winning such amounts is too small (358 individuals win an amount over 1,000 British pounds, and only
} 
our findings suggest that the direct wealth effect still outweighs the indirect health cost effect for smoking. The moderate increases in smoking are consistent with the notion that smoking is more unhealthy than drinking (moderately) but not sufficiently unhealthy that individuals reduce smoking in response to a wealth shock.

Table 7 summarizes the results for health by wealth subgroups and serves to test prediction 2. The most striking pattern is that the least healthy (bottom left and right quadrant) do not appear to change behavior in response to positive wealth shocks, with the exception of the most wealthy least healthy engaging more in exercise and the least wealthy least healthy more in social drinking. These results suggest that the least healthy have greater health costs than the most healthy.

If healthy individuals have lower health costs, we confirm the theoretical prediction that the most wealthy, least healthy (high health cost) do not change their unhealthy behaviors while the least wealthy most healthy (low health cost) increase their unhealthy behaviors, in response to a positive wealth shock. Additionally, and in line with hypothesis 2, conditional on being in good health (low health cost), individuals with less wealth respond stronger to a given wealth shock: the effect on smoking and drinking is generally larger for the least wealthy than for the most wealthy, and the effect on cigarette consumption is only apparent among the least wealthy (compare panel 2 with panel 3 in Tables 4 and $5)$.

The theory cannot unambiguously predict the relation between the response to a wealth shock and age. Increasing expenditures on medical care (health investment) toward the end of life suggests that the marginal cost of health investment $\pi_{I}(t)$ increases with age. Depending on the relationship between the change in health $\frac{\partial d}{\partial C_{u}} H(t)$ and age, the elderly could face a higher or lower health cost. The elderly seem to respond stronger to a positive wealth shock, which may suggest their health costs are lower. But another plausible explanation could be that they are more credit constrained or that they spend more of their windfall gain immediately because the remaining lifetime over which consumption can be smoothed is shorter for them.

Comparing our empirical results to the literature, we confirm the finding of Ettner (1996) that alcohol consumption increases with income and of Kenkel et al. (2011) that smoking and income are positively related in the US. We replicate the analysis of Apouey and Clark (2010) and confirm their results, but identify substantial differences in the characteristics between winners of small and large lottery amounts. When controlling for individual fixed effects we confirm their finding of a positive relation between social drinking and winning the lottery but we find that the effects on smoking and the number of cigarettes vanish. We also estimated models similar to those of Kim and Ruhm (2012) but find substantial differences in characteristics between inheritance recipients receiving amounts over 10,000 US dollars (the cut-off used by Kim and Ruhm, 2012) and recipients receiving inheritances below that amount. Including individual specific fixed effects renders all effects, except for drinking, insignificant. Given the differences

126 individuals win over 2,500 British pounds) to draw strong conclusions in this regard. 
in characteristics across small and big lottery winners and inheritance recipients, the estimates of both Apouey and Clark (2010) and Kim and Ruhm (2012) may be biased by unobserved heterogeneity.

The empirical findings that the response to a wealth shock depends on wealth, health, and on the unhealthiness of the good illustrate the importance of the health cost. These empirical findings cannot be explained simply by a smaller direct wealth effect among wealthier individuals, and provide empirical support for our theory.

Our theory is classical in the sense that it approximates human behavior by assuming individuals are rational and forward looking. In addition we have not modeled uncertainty such as health shocks. As a result, our theory predicts that individuals smooth consumption. Yet, empirically we found evidence that most of the wealth is spent within a few years following a wealth shock. This suggests that the observed responses are only representative of short-term effects of wealth shocks, more in line with a model in which individuals are credit constrained, or a behavioral model in which individuals spend most of their windfall immediately. Future theoretical work would benefit from modeling the role of credit constraints, and/or myopic behavior by, e.g., introducing hyperbolic discounting. A more comprehensive theory may also wish to incorporate the extent to which a good is addictive (e.g., Becker and Murphy 1988). 


\section{References}

Adams, P., M.D. Hurd, D. McFadden, A. Merrill, and T. Ribeiro (2003), "Healthy, Wealthy and Wise? Tests for Direct Causal Paths Between Health and Socioeconomic Status", Journal of Econometrics 112(1): 3-56.

Adda, J., J. Banks, and H.M. von Gaudecker (2009), "The impact of income shocks on health: evidence from cohort data", Journal of European Economic Association 7(6): 1361-1399.

Apouey, B., and A. Clark (2010). "Winning Big but Feeling No Better? The Effect of Lottery Prizes on Physical and Mental Health", PSE Working paper.

Arcidiacono, P., H. Sieg, and F. Sloan (2007). "Living rationally under the volcano? An empirical analysis of heavy drinking and smoking", International Economic Review, 48(1): 37-65.

Auld, C. (2005). "Smoking, Drinking, and Income", Journal of Human Resources, 40(2): 505-518.

Banks, J., R. Blundell, and J. P. Smith. (2003). "Wealth portfolios in the US and the UK", In Perspectives on the economics of aging, ed. D. Wise, 205-246. Chicago: University of Chicago Press.

Becker, G.S. and K. M. Murphy (1988). "A Theory of Rational Addiction", Journal of Political Economy, 96(4): 675-700.

Brown, J.R., C.C. Coile, and S.J. Weisbenner (2010). "The Effect of Inheritance Receipt on Retirement", Review of Economics and Statistics, 92(2): 425-434.

Caputo, M.R. (2005), Foundations of Dynamic Economic Analysis. Cambridge University Press.

Case, A. and A. Deaton (2005). "Broken Down by Work and Sex: How our Health Declines", in: David A. Wise (ed.), Analyses in the Economics of Aging, The University of Chicago Press, Chicago, 185-212.

Cawley, J., and C. Ruhm (2011). "The Economics of Risky Health Behaviors", In: Handbook of Health Economics Volume 2, ed. Mark V. Pauly, Thomas G. Mcguire and Pedro P. Barros, Chapter 3, pp. 95-199.

Clotfelter, C., and P. Cook (1989). "The Demand for Lottery Products", NBER Working 
Paper 2928.

Contoyannis, P. and A.M. Jones (2004). "Socio-economic status, health and lifestyle", Journal of Health Economics, 23(5): 965-995.

Cutler, D.M., and E. Glaeser (2005). "What explains differences in smoking, drinking, and other health-related behaviors?", American Economic Review 95(2):238-42.

Cutler, D.M., and A. Lleras-Muney (2008). "Education and health: evaluating theories and evidence" In: S.H. James, R.F. Schoeni, G.A. Kaplan, H. Pollack (Eds.), Making Americans Healthier: Social and Economic Policy as Health Policy, Russell Sage Foundation, New York.

Cutler, D.M., and A. Lleras-Muney (2010). "Understanding differences in health behaviors by education", Journal of Health Economics, 29(1): 1-28.

Cutler, D.M., A. Lleras-Muney, and T. Vogl (2011), "Socioeconomic Status and Health: Dimensions and Mechanisms", Oxford Handbook of Health Economics, eds. S. Glied and P.C. Smith, Oxford University Press.

Ehrlich, I. and H. Chuma (1990). "A Model of the Demand for Longevity and the Value of Life Extension", Journal of Political Economy, 98(4): 761-782.

Ettner, S.L. (1996). "New evidence on the relationship between income and health", Journal of Health Economics, 15(1): 67-85.

Forster, M. (2001). "The meaning of death: some simulations of a model of healthy and unhealthy consumption", Journal of Health Economics, 20(4): 613-638.

Fuller, T.D. (2011). "Moderate alcohol consumption and the risk of mortality", Demography, 48(3): 1105-1125.

Heckman, J. (1976), "A Life-Cycle Model of Earnings, Learning, and Consumption", Journal of Political Economy, 84(4): pp. 9-44.

Galama, T.J. (2011). "A Contribution to Health Capital Theory", RAND Working Paper, WR-831.

Galama, T.J. and H. van Kippersluis (2010). "A theory of socioeconomic disparities in health", RAND Working Paper, WR-773.

Gardner, J., and A.J. Oswald (2007). "Money and mental wellbeing: A longitudinal 
study of medium-sized lottery wins", Journal of Health Economics, 26(1): 49-60.

Gilman S.E., D.B. Abrams, and S.L. Buka (2003), "Socioeconomic status over the life course and stages of cigarette use: initiation, regular use, and cessation", Journal of Epidemiology and Community Health, 57:802-808.

Goodstein, R. (2008). "The Effect of Wealth on Labor Force Participation of Older Men", Unpublished manuscript, University of North Carolina, Chapel Hill, March 2008; www.unc.edu/ rmgoodst/wealth.pdf.

Grossman, M. (1972). "On the Concept of Health Capital and the Demand for Health", Journal of Political Economy, 80(2): 223-255.

Imbens, G., Rubin, D. and B. Sacerdote (2001). "Estimating the Effect of Unearned Income on Labor Supply, Earnings, Savings and Consumption: Evidence from a Survey of Lottery Players", American Economic Review 91(4): pp. 778-794.

Jones, A., X. Koolman, and N. Rice (2006). "Health-related non-response in the British Household Panel Survey and European Community Household Panel: using inverse-probability-weighted estimators in non-linear models", Journal of the Royal Statistical Society Series A, 169(3): 543-569.

Kawachi, I., N.E. Adler, and W.H. Dow (2010). "Money, schooling, and health: Mechanisms and causal evidence", Annals of the New York Academy of Sciences, 1186: 56-68.

Kenkel, D., M.D. Schmeiser, and C. Urban (2011). "Is Smoking Inferior? Evidence from Variation in the Earned Income Tax Credit", Working Paper available at SSRN: http://ssrn.com/abstract=1961196 or http://dx.doi.org/10.2139/ssrn.1961196.

Kim, B., and C.J. Ruhm (2012). "Inheritances, Health and Death", Health Economics, 21(2): 127-144.

Lindahl, M. (2005) "Estimating the Effect of Income on Health and Mortality Using Lottery Prizes as Exogenous Source of Variation in Income", Journal of Human Resources, 40: $144-168$.

Meer, J., D.L. Miller, and H. Rosen (2003). "Exploring the Health-Wealth Nexus", Journal of Health Economics, 22(5):713-720.

Michaud, P.C., and A. van Soest (2008). "Health and wealth of elderly couples: Causality tests using dynamic panel data models", Journal of Health Economics, 27(5): 1312-1325. 
OECD (1996). Education at a Glance - OECD Indicators, Paris: OECD.

Ratcliffe, A. (2012). "Wealth Effects or Economic Barometer: Why Do House Prices Matter for Psychological Health?", Sheffield Economics Research Papers Series 2012014.

Schwandt, H. (2011). "Is Wealth Causing Health? Evidence from Stock Market Induced Wealth Shocks", IZA Discussion Paper, Bonn.

Seierstad, A. and K. Sydsaeter (1987). "Optimal Control Theory With Economic Applications", In: Advanced Textbooks in Economics, Volume 24, Series Editors: C.J. Bliss and M.D. Intriligator, Elsevier, North Holland.

Snyder, S.E., and W.N. Evans (2006), "The Effect of Income on Mortality: Evidence from the Social Security Notch", Review of Economics and Statistics 88(3): 482-95.

Wagstaff, A. (1986). "The demand for health: Theory and applications", Journal of Epidemiology and Community Health, 40: 1-11. 
Table 1: Descriptive statistics of control variables by lottery winning status, BHPS

\begin{tabular}{|c|c|c|c|c|}
\hline Variable & Non-winners & Winners & Small Win & Big Win \\
\hline Log Household Wealth & 10.44 & $10.78^{* * *}$ & 10.75 & 11.21 \\
\hline Log Household Income & 10.03 & $10.13^{* * *}$ & 10.13 & 10.18 \\
\hline Age & 45.90 & $45.48^{* * *}$ & 45.44 & 46.17 \\
\hline Sex & 0.44 & $0.57^{* * *}$ & 0.56 & $0.61^{* * *}$ \\
\hline \multicolumn{5}{|l|}{ Region } \\
\hline Greater London (regions 1 and 2) & 0.05 & $0.06^{* * *}$ & 0.06 & 0.06 \\
\hline South (regions 3 and 4 ) & 0.17 & $0.24^{* * *}$ & 0.24 & 0.22 \\
\hline East (regions 5 and 6 ) & 0.08 & $0.11^{* * *}$ & 0.11 & $0.09^{*}$ \\
\hline West (regions 7 and 8) & 0.06 & $0.06^{* * *}$ & 0.06 & 0.07 \\
\hline North (regions 9 to 16 ) & 0.16 & $0.21^{* * *}$ & 0.21 & 0.21 \\
\hline Wales (region 17 ) & 0.16 & $0.11^{* * *}$ & 0.11 & 0.10 \\
\hline Scotland (region 18) & 0.17 & 0.18 & 0.18 & 0.18 \\
\hline Northern-Ireland (region 19) & 0.14 & $0.03^{* * *}$ & 0.03 & $0.07^{* * *}$ \\
\hline Household Size & 2.86 & $2.77^{* * *}$ & 2.78 & 2.76 \\
\hline Number of Children & 0.52 & $0.45^{* * *}$ & 0.45 & $0.54^{* * *}$ \\
\hline \multicolumn{5}{|l|}{ Level of Education } \\
\hline Post-secondary Education (levels 1 to 5) & 0.44 & $0.48^{* * *}$ & 0.48 & $0.43^{* * *}$ \\
\hline Completed Secondary Education (levels 6 and 7) & 0.26 & $0.27^{* * *}$ & 0.27 & 0.29 \\
\hline Less than Secondary Education (levels 8 to 13 ) & 0.29 & $0.25^{* * *}$ & 0.25 & $0.28^{*}$ \\
\hline \multicolumn{5}{|l|}{ Health Status } \\
\hline Excellent & 0.23 & $0.22^{* * *}$ & 0.22 & $0.25^{* *}$ \\
\hline Good & 0.46 & $0.49^{* * *}$ & 0.49 & 0.46 \\
\hline Fair & 0.21 & $0.20^{* * *}$ & 0.20 & 0.19 \\
\hline Poor & 0.08 & $0.07^{* * *}$ & 0.07 & 0.08 \\
\hline Very poor & 0.02 & 0.02 & 0.02 & 0.02 \\
\hline \multicolumn{5}{|l|}{ Marital Status } \\
\hline Married, Civil partnership & 0.53 & $0.57^{* * *}$ & 0.57 & $0.52^{* * *}$ \\
\hline Widowed & 0.08 & $0.06^{* * *}$ & 0.05 & $0.07^{* *}$ \\
\hline Never Married & 0.29 & 0.28 & 0.28 & 0.28 \\
\hline Separated, Divorced, Dissolved civil partnership & 0.10 & $0.09^{* * *}$ & 0.09 & $0.13^{* * *}$ \\
\hline \multicolumn{5}{|l|}{ Employment Status } \\
\hline Self-employed & 0.07 & $0.07^{* * *}$ & 0.07 & $0.15^{* * *}$ \\
\hline Employed, Maternity leave & 0.50 & $0.58^{* * *}$ & 0.58 & $0.55^{*}$ \\
\hline Disabled & 0.05 & $0.04^{* * *}$ & 0.04 & 0.03 \\
\hline Unemployed, Government training schemes & 0.04 & $0.02^{* * *}$ & 0.02 & 0.02 \\
\hline Retired & 0.22 & $0.19^{* * *}$ & 0.19 & 0.19 \\
\hline Full-time student, Family care, Other & 0.14 & $0.09^{* * *}$ & 0.09 & $0.06^{* * *}$ \\
\hline Number of observations & 149,333 & 16,155 & 15,274 & 881 \\
\hline
\end{tabular}

Notes: Author's calculations based on the 1997-2008 BHPS. Small Win refers to an amount won under 500 British pounds, and Big Win to an amount won above 500 British pounds. The asterisks denote whether the difference in means between non-winners (column 2) and winners (column 3) and between small winners (column 4) and big winners (column 5) are statistically significant. For ease of exposition, the 19 regions are subdivided into eight sub regions, the 13 educational categories into three, marital status into four and employment status into six categories (see Table C.1 for definitions of the 19 regions, 13 education levels, 7 marital status and 10 employment status categories). 
Table 2: Descriptive statistics of the control variables by inheritance receipt in the HRS

\begin{tabular}{|c|c|c|c|c|}
\hline Variable & No Inheritance & Inheritance & Small Inheritance & Big Inheritance \\
\hline Log Household Wealth & 11.31 & $12.71^{* * *}$ & 12.03 & $12.86^{* * *}$ \\
\hline Log Household Income & 10.43 & $11.29^{* * *}$ & 10.83 & $11.40^{* * *}$ \\
\hline Age & 65.81 & $62.12^{* * *}$ & 61.54 & $62.25^{* *}$ \\
\hline Sex & 0.42 & $0.46^{* * *}$ & 0.45 & 0.46 \\
\hline \multicolumn{5}{|l|}{ Race } \\
\hline White/Caucasian & 0.81 & $0.95^{* * *}$ & 0.92 & $0.95^{* * *}$ \\
\hline Black/African American & 0.14 & $0.03^{* * *}$ & 0.05 & $0.03^{* * *}$ \\
\hline Other & 0.04 & $0.02^{* * *}$ & 0.02 & 0.02 \\
\hline \multicolumn{5}{|l|}{ Census Region } \\
\hline Northeast & 0.16 & $0.14^{* * *}$ & 0.14 & 0.13 \\
\hline Midwest & 0.25 & $0.31^{* * *}$ & 0.32 & 0.31 \\
\hline South & 0.41 & $0.34^{* * *}$ & 0.36 & $0.33^{*}$ \\
\hline West & 0.17 & $0.21^{* * *}$ & 0.18 & $0.22^{* * *}$ \\
\hline Other & 0.00 & 0.00 & 0.00 & 0.00 \\
\hline Household Size & 2.29 & $2.27^{* * *}$ & 2.36 & $2.25^{* * *}$ \\
\hline Number of Children & 3.27 & $2.93^{* * *}$ & 3.09 & $2.90^{* * *}$ \\
\hline Years of Education & 12.18 & $13.86^{* * *}$ & 13.29 & $13.99^{* * *}$ \\
\hline \multicolumn{5}{|l|}{ Health Status } \\
\hline Excellent & 0.13 & $0.19^{* * *}$ & 0.17 & $0.20^{*}$ \\
\hline Very Good & 0.29 & $0.36^{* * *}$ & 0.34 & $0.37^{*}$ \\
\hline Good & 0.31 & $0.29^{* * *}$ & 0.30 & 0.29 \\
\hline Fair & 0.19 & $0.12^{* * *}$ & 0.14 & $0.11^{* *}$ \\
\hline Poor & 0.09 & $0.04^{* * *}$ & 0.05 & $0.04^{*}$ \\
\hline \multicolumn{5}{|l|}{ Marital Status } \\
\hline Married, Married spouse absent & 0.66 & $0.78^{* * *}$ & 0.75 & $0.79^{* * *}$ \\
\hline Partnered & 0.03 & 0.03 & 0.03 & 0.03 \\
\hline Separated/Divorced (categories 4 to 6 ) & 0.10 & $0.08^{* * *}$ & 0.10 & $0.07^{* *}$ \\
\hline Widow & 0.18 & $0.09^{* * *}$ & 0.10 & $0.08^{* *}$ \\
\hline Never Married & 0.03 & $0.02^{* *}$ & 0.02 & 0.02 \\
\hline Employment Status & 0.41 & $0.53^{* * *}$ & 0.53 & 0.53 \\
\hline Ever Smoked & 0.58 & 0.57 & 0.60 & $0.56^{* * *}$ \\
\hline Health Insurance & 0.83 & $0.79^{* * *}$ & 0.77 & $0.80^{* *}$ \\
\hline Mother died & 0.02 & $0.13^{* * *}$ & 0.11 & $0.13^{*}$ \\
\hline Father died & 0.01 & $0.05^{* * *}$ & 0.05 & $0.06^{*}$ \\
\hline Mother in law died & 0.02 & $0.10^{* * *}$ & 0.08 & $0.11^{* * *}$ \\
\hline Father in law died & 0.01 & $0.04^{* * *}$ & 0.03 & $0.04^{*}$ \\
\hline Widowed & 0.03 & $0.02^{* * *}$ & 0.02 & 0.02 \\
\hline Observations & 146,165 & 6,859 & 1,233 & 5,626 \\
\hline
\end{tabular}

Notes: Author's calculations on basis of the 1992-2010 HRS. The asterisks denote whether the difference in means between non-recipients (column 2) and recipients (column 3) and between small (column 4) and big recipients (column 5) are statistically significant. Marital status is grouped into 5 categories for exposition reasons (see Table C.2 for definitions of categories). 
Table 3: Descriptive statistics of the dependent and independent variables, for the full sample and for subgroups

\begin{tabular}{|c|c|c|c|c|c|c|c|}
\hline Outcome & Full sample & $\begin{array}{l}\text { Most Healthy } \\
\text { Most Wealthy }\end{array}$ & $\begin{array}{l}\text { Most Healthy } \\
\text { Least Wealthy }\end{array}$ & $\begin{array}{l}\text { Least Healthy } \\
\text { Most Wealthy }\end{array}$ & $\begin{array}{l}\text { Least Healthy } \\
\text { Least Wealthy }\end{array}$ & Below age 50 & Above age 50 \\
\hline \multicolumn{8}{|l|}{ BHPS } \\
\hline Log Imputed Household Wealth & 10.78 & 11.88 & 9.97 & 11.06 & 8.64 & 10.93 & 10.61 \\
\hline Log Household Income & 10.13 & 10.45 & 9.88 & 10.23 & 9.63 & 10.28 & 10.00 \\
\hline Log Amount Won & 3.70 & 3.73 & 3.73 & 3.60 & 3.66 & 3.73 & 3.67 \\
\hline Log Amount Won (Big Win) & 7.33 & 7.39 & 7.30 & 7.26 & 7.26 & 7.37 & 7.28 \\
\hline Relative Amount Won (\%) & 0.08 & 0.03 & 0.20 & 0.06 & 0.69 & 0.07 & 0.10 \\
\hline Relative Amount Won (Big Win, \%) & 2.07 & 0.86 & 5.08 & 1.08 & 27.80 & 2.17 & 1.91 \\
\hline Log Food Expenditures & 3.20 & 3.58 & 3.09 & 3.19 & 2.51 & 3.55 & 2.80 \\
\hline Smoking (\%) & 26.07 & 16.31 & 31.22 & 24.33 & 40.81 & 30.61 & 21.10 \\
\hline Log Number of Cigarettes & 2.39 & 2.20 & 2.42 & 2.37 & 2.57 & 2.54 & 2.68 \\
\hline Drinking Out & 3.21 & 3.43 & 3.24 & 3.09 & 2.76 & 3.68 & 2.69 \\
\hline Sports & 3.78 & 4.14 & 3.84 & 3.58 & 3.01 & 4.09 & 3.45 \\
\hline \multicolumn{8}{|l|}{ HRS } \\
\hline Log Household Wealth & 12.71 & 13.46 & 11.88 & 12.88 & 10.84 & & \\
\hline Log Amount Inherited & 10.59 & 10.91 & 10.22 & 10.62 & 9.93 & & \\
\hline Relative Amount Inherited (\%) & 11.97 & 7.77 & 18.90 & 10.42 & 40.25 & & \\
\hline Log Food Expenditures & 4.64 & 4.86 & 4.62 & 4.70 & 4.37 & & \\
\hline Smoking (\%) & 15.84 & 10.61 & 17.60 & 13.79 & 21.61 & & \\
\hline Log Number of Cigarettes & 2.18 & 2.16 & 2.19 & 2.18 & 2.17 & & \\
\hline Drinking $(\%)$ & 49.60 & 66.97 & 51.38 & 48.26 & 31.57 & & \\
\hline Log Number of Drinks & 1.04 & 1.17 & 1.01 & 0.97 & 0.88 & & \\
\hline Heavy Drinking (\%) & 14.14 & 10.74 & 15.40 & 13.46 & 20.81 & & \\
\hline Light Physical Activity & 3.33 & 3.60 & 3.45 & 3.24 & 3.01 & & \\
\hline Log Out-of-pocket Expenditures & 6.41 & 6.74 & 6.02 & 7.06 & 5.73 & & \\
\hline
\end{tabular}

Author's calculations on basis of the 1997-2008 BHPS and 1992-2010 HRS. Note that Log Household Wealth and Log Household Income are calculated on basis of the sample of lottery winners (BHPS) or inheritance recipients (HRS). Relative amounts are calculated by the ratio of $\exp (\log$ amount won $) / \exp (\log$ household wealth $)$. 
Table 4: Estimates of the effect of lottery winnings - BHPS

\begin{tabular}{|c|c|c|c|}
\hline Outcome & $\begin{array}{c}\text { FE Lottery } \\
\text { Won }\end{array}$ & $\begin{array}{c}\text { FE Big } \\
\text { Lottery Won }\end{array}$ & $\begin{array}{l}\text { FE Log Amount } \\
\text { Lottery Won }\end{array}$ \\
\hline \multicolumn{4}{|l|}{ Full sample (panel 1) } \\
\hline Log Food Expenditures & 0.0134 & $0.0959^{* *}$ & $0.0069^{* *}$ \\
\hline$N=134,829$ & $(0.0122)$ & $(0.0388)$ & $(0.0030)$ \\
\hline Smoking & 0.0003 & -0.0047 & 0.0002 \\
\hline$N=134,829$ & $(0.0024)$ & $(0.0091)$ & $(0.0006)$ \\
\hline - Among Smokers & -0.0032 & 0.0115 & -0.0005 \\
\hline$N=34,678$ & $(0.0062)$ & $(0.0237)$ & $(0.0015)$ \\
\hline - Among Non-Smokers & -0.0016 & -0.0014 & -0.0003 \\
\hline$N=100,151$ & $(0.0016)$ & $(0.0053)$ & $(0.0004)$ \\
\hline Log Number of Cigarettes & -0.0112 & 0.0480 & -0.0014 \\
\hline$N=34,678$ & $(0.0173)$ & $(0.0601)$ & $(0.0042)$ \\
\hline Drinking Out & $0.0432^{* * *}$ & $0.1076^{*}$ & $0.0145^{* * *}$ \\
\hline$N=74,142$ & $(0.0138)$ & $(0.0566)$ & $(0.0036)$ \\
\hline Sports & $0.0588^{* * *}$ & -0.0424 & $0.0114^{* *}$ \\
\hline$N=61,848$ & $(0.0215)$ & $(0.0842)$ & $(0.0054)$ \\
\hline \multicolumn{4}{|c|}{ Most Healthy and Most Wealthy (panel 2) } \\
\hline Log Food Expenditures & 0.0158 & 0.0089 & 0.0057 \\
\hline$N=49,252$ & $(0.0169)$ & $(0.0478)$ & $(0.0041)$ \\
\hline Smoking & 0.0013 & -0.0002 & 0.0004 \\
\hline$N=49,252$ & $(0.0033)$ & $(0.0106)$ & $(0.0008)$ \\
\hline - Among Smokers & 0.0149 & 0.0272 & 0.0041 \\
\hline$N=7,838$ & $(0.0130)$ & $(0.0393)$ & $(0.0031)$ \\
\hline - Among Non-Smokers & -0.0034 & 0.0025 & -0.0006 \\
\hline$N=41,414$ & $(0.0023)$ & $(0.0036)$ & $(0.0005)$ \\
\hline Log Number of Cigarettes & 0.0319 & 0.0568 & 0.0077 \\
\hline$N=7,838$ & $(0.0364)$ & $(0.1070)$ & $(0.0089)$ \\
\hline Drinking Out & 0.0212 & $0.1730^{*}$ & $0.0105^{* *}$ \\
\hline$N=27,132$ & $(0.0199)$ & $(0.0922)$ & $(0.0053)$ \\
\hline Sports & -0.0036 & -0.0748 & -0.0023 \\
\hline$N=22,303$ & $(0.0304)$ & $(0.1264)$ & $(0.0074)$ \\
\hline \multicolumn{4}{|c|}{ Most Healthy and Least Wealthy (panel 3) } \\
\hline Log Food Expenditures & 0.0096 & 0.0529 & 0.0073 \\
\hline$N=44,414$ & $(0.0238)$ & $(0.0748)$ & $(0.0057)$ \\
\hline Smoking & 0.0045 & 0.0087 & $0.0020^{*}$ \\
\hline$N=44,414$ & $(0.0047)$ & $(0.0193)$ & $(0.0012)$ \\
\hline - Among Smokers & -0.0074 & $0.0711^{*}$ & 0.0006 \\
\hline$N=13,831$ & $(0.0109)$ & $(0.0391)$ & $(0.0026)$ \\
\hline - Among Non-Smokers & 0.0005 & -0.0027 & 0.0001 \\
\hline$N=30,583$ & $(0.0029)$ & $(0.0150)$ & $(0.0007)$ \\
\hline Log Number of Cigarettes & -0.0308 & 0.1451 & -0.0017 \\
\hline$N=13,831$ & $(0.0295)$ & $(0.0970)$ & $(0.0068)$ \\
\hline Drinking Out & $0.0517^{* *}$ & 0.0821 & $0.0156^{* *}$ \\
\hline$N=24,441$ & $(0.0259)$ & $(0.0943)$ & $(0.0066)$ \\
\hline Sports & $0.0784^{*}$ & 0.0147 & $0.0181^{*}$ \\
\hline$N=20,383$ & $(0.0428)$ & $(0.1668)$ & $(0.0110)$ \\
\hline
\end{tabular}


Table 4: (continued)

\begin{tabular}{|c|c|c|c|}
\hline Outcome & $\begin{array}{c}\text { FE Lottery } \\
\text { Won }\end{array}$ & $\begin{array}{c}\text { FE Big } \\
\text { Lottery Won }\end{array}$ & $\begin{array}{c}\text { FE Log Amount } \\
\text { Lottery Won }\end{array}$ \\
\hline \multicolumn{4}{|c|}{ Least Healthy and Most Wealthy (panel 4) } \\
\hline Log Food Expenditures & 0.0279 & 0.1572 & $0.0137^{*}$ \\
\hline$N=18,996$ & $(0.0307)$ & $(0.1343)$ & $(0.0077)$ \\
\hline Smoking & -0.0060 & $-0.0494^{*}$ & -0.0026 \\
\hline$N=18,996$ & $(0.0065)$ & $(0.0298)$ & $(0.0017)$ \\
\hline - Among Smokers & -0.0024 & $-0.1230^{*}$ & -0.0043 \\
\hline$N=4,563$ & $(0.0163)$ & $(0.0736)$ & $(0.0042)$ \\
\hline - Among Non-Smokers & -0.0015 & -0.0130 & -0.0007 \\
\hline$N=14,433$ & $(0.0041)$ & $(0.0135)$ & $(0.0011)$ \\
\hline Log Number of Cigarettes & 0.0217 & -0.2287 & -0.0034 \\
\hline$N=4,563$ & $(0.0431)$ & $(0.1812)$ & $(0.0113)$ \\
\hline Drinking Out & $0.0687^{*}$ & 0.0969 & 0.0160 \\
\hline$N=10,468$ & $(0.0385)$ & $(0.1600)$ & $(0.0100)$ \\
\hline Sports & 0.0914 & 0.1319 & 0.0232 \\
\hline$N=8,842$ & $(0.0564)$ & $(0.2169)$ & $(0.0142)$ \\
\hline \multicolumn{4}{|c|}{ Least Healthy and Least Wealthy (panel 5) } \\
\hline Log Food Expenditures & -0.0088 & $0.3200^{* *}$ & -0.0006 \\
\hline$N=19,104$ & $(0.0432)$ & $(0.1257)$ & $(0.0105)$ \\
\hline Smoking & -0.0029 & -0.0024 & -0.0012 \\
\hline$N=19,104$ & $(0.0072)$ & $(0.0216)$ & $(0.0017)$ \\
\hline - Among Smokers & -0.0084 & 0.0197 & -0.0017 \\
\hline$N=7,819$ & $(0.0116)$ & $(0.0450)$ & $(0.0029)$ \\
\hline - Among Non-Smokers & -0.0015 & -0.0202 & -0.0008 \\
\hline$N=11,285$ & $(0.0051)$ & $(0.0129)$ & $(0.0012)$ \\
\hline Log Number of Cigarettes & -0.0298 & 0.1140 & -0.0039 \\
\hline$N=7,819$ & $(0.0357)$ & $(0.1323)$ & $(0.0090)$ \\
\hline Drinking Out & $0.0790^{*}$ & 0.1803 & $0.0312^{* * *}$ \\
\hline$N=10,509$ & $(0.0465)$ & $(0.1657)$ & $(0.0118)$ \\
\hline Sports & $0.1442^{* *}$ & -0.3022 & 0.0229 \\
\hline$N=8,904$ & $(0.0722)$ & $(0.2337)$ & $(0.0181)$ \\
\hline \multicolumn{4}{|c|}{ Below 50 years old (panel 6) } \\
\hline Log Food Expenditures & 0.0045 & $0.0851^{*}$ & $0.0059^{* * *}$ \\
\hline$N=68,437$ & $(0.0146)$ & $(0.0516)$ & $(0.0036)$ \\
\hline Smoking & 0.0007 & 0.0014 & 0.0003 \\
\hline$N=68,437$ & $(0.0037)$ & $(0.0143)$ & $(0.0009)$ \\
\hline - Among Smokers & -0.0019 & 0.0199 & -0.0000 \\
\hline$N=20,740$ & $(0.0082)$ & $(0.0334)$ & $(0.0021)$ \\
\hline - Among Non-Smokers & -0.0036 & 0.0040 & -0.0008 \\
\hline$N=47,697$ & $(0.0028)$ & $(0.0085)$ & $(0.0007)$ \\
\hline Log Number of Cigarettes & -0.0217 & 0.0639 & -0.0028 \\
\hline$N=20,740$ & $(0.0229)$ & $(0.0841)$ & $(0.0057)$ \\
\hline Drinking Out & $0.0318^{*}$ & 0.0421 & $0.0103^{* *}$ \\
\hline$N=37,691$ & $(0.0180)$ & $(0.0748)$ & $(0.0046)$ \\
\hline Sports & 0.0455 & 0.0026 & 0.0078 \\
\hline$N=30,658$ & $(0.0291)$ & $(0.1167)$ & $(0.0071)$ \\
\hline
\end{tabular}


Table 4: (continued)

\begin{tabular}{cccc}
\hline \hline Outcome & $\begin{array}{c}\text { FE Lottery } \\
\text { Won }\end{array}$ & $\begin{array}{c}\text { FE Big } \\
\text { Lottery Won }\end{array}$ & $\begin{array}{c}\text { FE Log Amount } \\
\text { Lottery Won }\end{array}$ \\
\hline Above 50 years old (panel 7) & & \\
Log Food Expenditures & 0.0186 & $0.1087^{*}$ & 0.0073 \\
$N=66,392$ & $(0.0192)$ & $(0.0576)$ & $(0.0047)$ \\
Smoking & -0.0004 & -0.0105 & -0.0001 \\
$N=66,392$ & $(0.0030)$ & $(0.0114)$ & $(0.0008)$ \\
- Among Smokers & -0.0067 & -0.0163 & -0.0019 \\
$N=13,938$ & $(0.0094)$ & $(0.0321)$ & $(0.0023)$ \\
- Among Non-Smokers & -0.0002 & -0.0045 & -0.0000 \\
$N=52,454$ & $(0.0016)$ & $(0.0068)$ & $(0.0004)$ \\
Log Number of Cigarettes & -0.0041 & -0.0014 & -0.0013 \\
$N=13,938$ & $(0.0264)$ & $(0.0850)$ & $(0.0064)$ \\
Drinking Out & $0.0537^{* * *}$ & $0.1678^{* *}$ & $0.0183^{* * *}$ \\
$N=36,451$ & $(0.0207)$ & $(0.0826)$ & $(0.0054)$ \\
Sports & $0.0703^{* *}$ & -0.0608 & $0.0148^{*}$ \\
$N=31,190$ & $(0.0312)$ & $(0.1193)$ & $(0.0079)$ \\
\hline \hline
\end{tabular}

Notes: Author's calculations on basis of the 1997-2008 BHPS. "FE Lottery Won" refers to model (17), "FE Big Lottery Won" refers to model (18), and "FE Log Amount Lottery Won" refers to model (19). Note that all models include the same set of control variables as in Table C.1. "Most Healthy" refer to those initially in "Excellent" or "Good" self-reported health, and "Least Healthy" refer to those initially in "Fair", "Poor", or "Very Poor" self-reported health. "Most Wealthy" and "Least Wealthy" include individuals that at first observation are, respectively, above and below the age-wave-specific median imputed household wealth. "Below 50 years old" are those that were below age 50 in 2008, and "Above 50 years old" are those that were aged 50 or older in 2008. 
Table 5: Estimates of the effect of inheritance receipt - HRS

\begin{tabular}{|c|c|c|c|}
\hline Outcome & FE Inheritance & FE Big Inheritance & $\begin{array}{l}\text { FE Log Amount } \\
\text { Inherited }\end{array}$ \\
\hline \multicolumn{4}{|l|}{ Full sample (panel 1) } \\
\hline Log Food Expenditures & $0.0487^{*}$ & -0.0256 & $0.0051^{* *}$ \\
\hline$N=77,720$ & $(0.0256)$ & $(0.0666)$ & $(0.0025)$ \\
\hline Smoking & $0.0095^{* * *}$ & -0.0103 & $0.0009^{* * *}$ \\
\hline$N=118,604$ & $(0.0029)$ & $(0.0077)$ & $(0.0003)$ \\
\hline - Among Smokers & 0.0232 & -0.0459 & 0.0021 \\
\hline$N=18,693$ & $(0.0157)$ & $(0.0308)$ & $(0.0015)$ \\
\hline - Among Non-Smokers & 0.0021 & 0.0011 & 0.0002 \\
\hline$N=99,600$ & $(0.0016)$ & $(0.0042)$ & $(0.0001)$ \\
\hline Log Number of Cigarettes & $0.1044^{*}$ & -0.1622 & $0.0094^{*}$ \\
\hline$N=16,034$ & $(0.0533)$ & $(0.1082)$ & $(0.0051)$ \\
\hline Drinking & $0.0137^{* * *}$ & $0.0224^{*}$ & $0.0012^{* *}$ \\
\hline$N=118,604$ & $(0.0052)$ & $(0.0133)$ & $(0.0005)$ \\
\hline Log Number of Drinks & 0.0107 & -0.0004 & 0.0006 \\
\hline$N=54,126$ & $(0.0148)$ & $(0.0374)$ & $(0.0013)$ \\
\hline Heavy Drinking & 0.0054 & 0.0013 & 0.0006 \\
\hline$N=54,126$ & $(0.0058)$ & $(0.0141)$ & $(0.0005)$ \\
\hline Light Physical Activity & -0.0080 & $-0.1177^{* * *}$ & -0.0012 \\
\hline$N=57,633$ & $(0.0208)$ & $(0.0490)$ & $(0.0019)$ \\
\hline Log Out-of-Pocket Med. Exp. & 0.0448 & 0.0358 & $0.0050^{*}$ \\
\hline$N=108,333$ & $(0.0316)$ & $(0.0785)$ & $(0.0029)$ \\
\hline \multicolumn{4}{|c|}{ Most Healthy and Most Wealthy (panel 2) } \\
\hline Log Food Expenditures & 0.0105 & & 0.0023 \\
\hline$N=20,554$ & $(0.0385)$ & & $(0.0036)$ \\
\hline Smoking & $0.0105^{* * *}$ & & $0.0009^{* * *}$ \\
\hline$N=31,278$ & $(0.0038)$ & & $(0.0003)$ \\
\hline - Among Smokers & 0.0199 & & 0.0016 \\
\hline$N=3,395$ & $(0.0281)$ & & $(0.0026)$ \\
\hline - Among Non-Smokers & $0.0039^{*}$ & & $0.0004^{* *}$ \\
\hline$N=27,789$ & $(0.0021)$ & & $(0.0002)$ \\
\hline Log Number of Cigarettes & 0.0498 & & 0.0049 \\
\hline$N=2,901$ & $(0.0890)$ & & $(0.0080)$ \\
\hline Drinking & $0.0179^{* *}$ & & $0.0014^{* *}$ \\
\hline$N=31,278$ & $(0.0075)$ & & $(0.0007)$ \\
\hline Log Number of Drinks & 0.0167 & & 0.0006 \\
\hline$N=19,073$ & $(0.0188)$ & & $(0.0017)$ \\
\hline Heavy Drinking & 0.0065 & & 0.0005 \\
\hline$N=19,073$ & $(0.0079)$ & & $(0.0007)$ \\
\hline Light Physical Activity & $-0.0636^{* *}$ & & $-0.0055^{*}$ \\
\hline$N=15,498$ & $(0.0309)$ & & $(0.0028)$ \\
\hline Log Out-of-Pocket Med. Exp. & 0.0594 & & $0.0066^{*}$ \\
\hline$N=28,514$ & $(0.0437)$ & & $(0.0039)$ \\
\hline
\end{tabular}


Table 5: (continued)

\begin{tabular}{|c|c|c|}
\hline Outcome & $\begin{array}{ll}\text { FE Inheritance } & \text { FE Big Inheritance }\end{array}$ & $\begin{array}{l}\text { FE Log Amount } \\
\text { Inherited }\end{array}$ \\
\hline \multicolumn{3}{|c|}{ Most Healthy and Least Wealthy (panel 3) } \\
\hline Log Food Expenditures & 0.0458 & 0.0042 \\
\hline$N=19,295$ & $(0.0453)$ & $(0.0043)$ \\
\hline Smoking & $0.0225^{* * *}$ & $0.0021^{* * *}$ \\
\hline$N=29,215$ & $(0.0069)$ & $(0.0006)$ \\
\hline - Among Smokers & $0.0689^{* *}$ & $0.0061^{* *}$ \\
\hline$N=5,152$ & $(0.0304)$ & $(0.0030)$ \\
\hline - Among Non-Smokers & 0.0012 & 0.0001 \\
\hline$N=24,004$ & $(0.0034)$ & $(0.0003)$ \\
\hline Log Number of Cigarettes & $0.2429^{* *}$ & $0.0225^{* *}$ \\
\hline$N=4,423$ & $(0.1033)$ & $(0.0101)$ \\
\hline Drinking & $0.0285^{* * *}$ & $0.0030^{* * *}$ \\
\hline$N=29,215$ & $(0.0108)$ & $(0.0010)$ \\
\hline Log Number of Drinks & 0.0272 & 0.0028 \\
\hline$N=13,587$ & $(0.0311)$ & $(0.0030)$ \\
\hline Heavy Drinking & -0.0045 & -0.0003 \\
\hline$N=13,587$ & $(0.0118)$ & $(0.0012)$ \\
\hline Light Physical Activity & -0.0417 & -0.0035 \\
\hline$N=14,319$ & $(0.0427)$ & $(0.0042)$ \\
\hline Log Out-of-Pocket Med. Exp. & 0.0339 & 0.0027 \\
\hline$N=26,527$ & $(0.0718)$ & $(0.0068)$ \\
\hline \multicolumn{3}{|c|}{ Least Healthy and Most Wealthy (panel 4) } \\
\hline Log Food Expenditures & $0.0979^{* *}$ & $0.0096^{* *}$ \\
\hline$N=20,475$ & $(0.0471)$ & $(0.0045)$ \\
\hline Smoking & -0.0015 & -0.0000 \\
\hline$N=31,058$ & $(0.0055)$ & $(0.0005)$ \\
\hline - Among Smokers & 0.0008 & 0.0008 \\
\hline$N=4,379$ & $(0.0311)$ & $(0.0030)$ \\
\hline - Among Non-Smokers & 0.0001 & 0.0001 \\
\hline$N=26,586$ & $(0.0032)$ & $(0.0003)$ \\
\hline Log Number of Cigarettes & 0.1246 & 0.0122 \\
\hline$N=3,737$ & $(0.1066)$ & $(0.0101)$ \\
\hline Drinking & -0.0001 & -0.0002 \\
\hline$N=31,058$ & $(0.0102)$ & $(0.0009)$ \\
\hline Log Number of Drinks & -0.0161 & -0.0014 \\
\hline$N=13,836$ & $(0.0304)$ & $(0.0027)$ \\
\hline Heavy Drinking & 0.0010 & 0.0003 \\
\hline$N=13,836$ & $(0.0125)$ & $(0.0011)$ \\
\hline Light Physical Activity & $0.1146^{* * *}$ & $0.0086^{* *}$ \\
\hline$N=15,012$ & $(0.0417)$ & $(0.0038)$ \\
\hline Log Out-of-Pocket Med. Exp. & 0.0345 & 0.0051 \\
\hline$N=28,524$ & $(0.0570)$ & $(0.0052)$ \\
\hline
\end{tabular}


Table 5: (continued)

\begin{tabular}{|c|c|c|}
\hline Outcome & FE Inheritance $\quad$ FE Big Inheritance & $\begin{array}{l}\text { FE Log Amount } \\
\text { Inherited }\end{array}$ \\
\hline \multicolumn{3}{|c|}{ Least Healthy and Least Wealthy (panel 5) } \\
\hline Log Food Expenditures & 0.1035 & 0.0096 \\
\hline$N=17,396$ & $(0.0750)$ & $(0.0073)$ \\
\hline Smoking & 0.0045 & 0.0002 \\
\hline$N=27,053$ & $(0.0107)$ & $(0.0011)$ \\
\hline - Among Smokers & 0.0072 & 0.0002 \\
\hline$N=5,767$ & $(0.0387)$ & $(0.0041)$ \\
\hline - Among Non-Smokers & 0.0021 & 0.0002 \\
\hline$N=21,221$ & $(0.0065)$ & $(0.0006)$ \\
\hline Log Number of Cigarettes & 0.0421 & 0.0020 \\
\hline$N=4,973$ & $(0.1331)$ & $(0.0135)$ \\
\hline Drinking & -0.0029 & -0.0003 \\
\hline$N=27,053$ & $(0.0174)$ & $(0.0016)$ \\
\hline Log Number of Drinks & -0.0149 & -0.0014 \\
\hline$N=7,630$ & $(0.0647)$ & $(0.0063)$ \\
\hline Heavy Drinking & 0.0464 & $0.0051^{*}$ \\
\hline$N=7,630$ & $(0.0285)$ & $(0.0027)$ \\
\hline Light Physical Activity & 0.0489 & 0.0030 \\
\hline$N=12,804$ & $(0.0790)$ & $(0.0077)$ \\
\hline Log Out-of-Pocket Med. Exp. & -0.0564 & -0.0089 \\
\hline$N=24,768$ & $(0.1266)$ & $(0.0126)$ \\
\hline
\end{tabular}

${ }^{*}$ p-value $<0.1,{ }^{* *}$ p-value $<0.05, * * * \mathrm{p}$-value $<0.01$

Notes: Author's calculations on basis of the 1992-2010 HRS. "FE Inheritance" refers to model (17), "FE Big Inheritance" refers to model (18), and "FE Log Amount Inherited" to model (19). Note that all models include the same set of control variables as in Table C.2. "Most Healthy" are those in "Excellent" or "Very Good" self-reported health at first observation in the panel, and "Least Healthy" are those in "Good", "Fair", or "Poor" self-reported health at first observation. "Most Wealthy" and "Least Wealthy" include individuals that at first observation are, respectively, above and below the age-wave-specific median household wealth. 
Table 6: Summary of full sample effects

\begin{tabular}{lcc}
\hline \hline Outcome & BHPS & HRS \\
\hline Smoking & & + \\
\# Cigarettes & & + \\
Drinking & + & + \\
\# Drinks & N/A & \\
Heavy Drinking & N/A & \\
Exercise & + & \\
OOP & N/A & \\
\hline \hline
\end{tabular}

Notes: This table summarizes the results for the full BHPS and HRS samples, obtained from panel 1 of Table 4 and panel 1 of Table 5. A + indicates a positive response and a - a negative response. Effects are included if at least one effect size is recorded at a p-value of $<0.05$ or in two specifications at a p-value of at least $<0.1$. OOP $=$ out-of-pocket medical expenditures.

Table 7: Summary of wealth by health subgroup effects

\begin{tabular}{|c|c|c|c|c|c|}
\hline & & \multicolumn{2}{|c|}{ Most Wealthy } & \multicolumn{2}{|c|}{ Least Wealthy } \\
\hline & Outcome & BHPS & HRS & BHPS & HRS \\
\hline Most Healthy & $\begin{array}{l}\text { Smoking } \\
\text { \# Cigarettes } \\
\text { Drinking } \\
\text { \# Drinks } \\
\text { Heavy Drinking } \\
\text { Exercise } \\
\text { OOP }\end{array}$ & $\begin{array}{c}+ \\
\mathrm{N} / \mathrm{A} \\
\mathrm{N} / \mathrm{A} \\
\mathrm{N} / \mathrm{A}\end{array}$ & $\begin{array}{l}+ \\
+ \\
-\end{array}$ & $\begin{array}{c}+ \\
\mathrm{N} / \mathrm{A} \\
\mathrm{N} / \mathrm{A} \\
+ \\
\mathrm{N} / \mathrm{A}\end{array}$ & $\begin{array}{l}+ \\
+ \\
+\end{array}$ \\
\hline Least Healthy & $\begin{array}{l}\text { Smoking } \\
\text { \# Cigs. } \\
\text { Drinking } \\
\text { \# Drinks } \\
\text { Heavy Drinking } \\
\text { Exercise } \\
\text { OOP }\end{array}$ & $\begin{array}{l}\mathrm{N} / \mathrm{A} \\
\mathrm{N} / \mathrm{A} \\
\mathrm{N} / \mathrm{A}\end{array}$ & + & $\begin{array}{c}+ \\
\mathrm{N} / \mathrm{A} \\
\mathrm{N} / \mathrm{A} \\
\mathrm{N} / \mathrm{A}\end{array}$ & \\
\hline
\end{tabular}

Notes: This table summarizes the results for wealth by health subgroups of the BHPS and HRS panels, obtained from panels 2 to 5 of Table 4 and panels 2 to 5 of Table 5 . Rest as in Table 6 . 


\section{A First-order conditions}

Associated with the Hamiltonian (equation 4) we have the following conditions:

$$
\begin{aligned}
& \dot{q}_{A}(t)=-\frac{\partial \Im(t)}{\partial A(t)} \Rightarrow \\
& \dot{q}_{A}(t)=-\delta q_{A}(t) \Leftrightarrow \\
& q_{A}(t)=q_{A}(0) e^{-\delta t}, \\
& \dot{q}_{H}(t)=-\frac{\partial \Im(t)}{\partial H(t)} \Rightarrow \\
& \dot{q}_{H}(t)=q_{H}(t) d(t)-\frac{\partial U(t)}{\partial H(t)} e^{-\beta t}-q_{A}(0) \frac{\partial Y(t)}{\partial H(t)} e^{-\delta t} \Leftrightarrow \\
& q_{H}(t)=q_{H}(0) e^{\int_{0}^{t} d(x) d x}-\int_{0}^{t}\left[\frac{\partial U(s)}{\partial H(s)} e^{-\beta s}+q_{A}(0) \frac{\partial Y(s)}{\partial H(s)} e^{-\delta s}\right] e^{\int_{s}^{t} d(x) d x} d s, \\
& \frac{\partial \Im(t)}{\partial I(t)}=0 \Rightarrow \\
& q_{H}(t)=q_{A}(0)\left\{\frac{p_{I}(t) I(t)^{1-\alpha}}{\alpha \mu_{I}(t)}\right\} e^{-\delta t} \\
& \equiv q_{A}(0) \pi_{I}(t) e^{-\delta t} \\
& \frac{\partial \Im(t)}{\partial C_{h}(t)}=0 \Rightarrow \\
& \frac{\partial U(t)}{\partial C_{h}(t)}=q_{A}(0) p_{C_{h}}(t) e^{(\beta-\delta) t}+q_{H}(t) \frac{\partial d(t)}{\partial C_{h}(t)} H(t) e^{\beta t} \\
& \equiv q_{A}(0) p_{C_{h}}(t) e^{(\beta-\delta) t}-q_{H}(t) \frac{\varphi_{d C_{h}}(t)}{\pi_{I}(t)} e^{\beta t}, \\
& \frac{\partial \Im(t)}{\partial C_{u}(t)}=0 \Rightarrow \\
& \frac{\partial U(t)}{\partial C_{u}(t)}=q_{A}(0) p_{C_{u}}(t) e^{(\beta-\delta) t}+q_{H}(t) \frac{\partial d(t)}{\partial C_{u}(t)} H(t) e^{\beta t} \\
& \equiv q_{A}(0) p_{C_{u}}(t) e^{(\beta-\delta) t}+q_{H}(t) \frac{\pi_{d C_{u}}(t)}{\pi_{I}(t)} e^{\beta t} .
\end{aligned}
$$

Equation (23) combined with (22) provides the first-order condition for maximization of the Hamiltonian (4) with respect to healthy consumption (equation 7). Similarly, equation (24) combined with (22) provides the first-order condition for maximization of the Hamiltonian (4) with respect to unhealthy consumption (equation 10). Using (22) to obtain an expression for $\dot{q}_{H}(t)$ and substituting the results for $q_{H}(t)$ and $\dot{q}_{H}(t)$ in $(21)$ we find the first-order condition for maximization of the Hamiltonian (4) with respect to investment in health (equation 5). 


\section{B Comparative Dynamics}

We are interested in the comparative dynamic effect of an increase in initial wealth $A_{0}$ on the control variables healthy consumption and unhealthy consumption. We start by taking the derivative of the first-order conditions with respect to initial wealth.

For the control variable healthy consumption the comparative dynamic effect of initial wealth $A_{0}$ is obtained from (7):

$$
\begin{aligned}
& {\left[\frac{\partial^{2} U}{\partial C_{h}^{2}}-q_{A}(0) \pi_{I}(t) \frac{\partial^{2} d}{\partial C_{h}^{2}} H(t) e^{(\beta-\delta) t}\right] \frac{\partial C_{h}}{\partial A_{0}} } \\
= & {\left[\frac{1}{q_{A}(0)} \frac{\partial U}{\partial C_{h}}\right] \times \frac{\partial q_{A}(0)}{\partial A_{0}} } \\
+ & {\left[q_{A}(0) \frac{\partial d}{\partial C_{h}} H(t) e^{(\beta-\delta) t}\right] \times \frac{\partial \pi_{I}}{\partial A_{0}} } \\
+ & {\left[q_{A}(0) \pi_{I}(t) \frac{\partial^{2} d}{\partial C_{u} \partial C_{h}} H(t) e^{(\beta-\delta) t}-\frac{\partial^{2} U}{\partial C_{u} \partial C_{h}}\right] \times \frac{\partial C_{u}}{\partial A_{0}} } \\
+ & {\left[q_{A}(0) \pi_{I}(t) \frac{\partial d}{\partial C_{h}} e^{(\beta-\delta) t}-\frac{\partial^{2} U}{\partial H \partial C_{h}}\right] \times \frac{\partial H}{\partial A_{0}} . }
\end{aligned}
$$

Or,

$$
\frac{\partial C_{h}}{\partial A_{0}} \equiv b_{q}(t) \frac{\partial q_{A}(0)}{\partial A_{0}}+b_{\pi}(t) \frac{\partial \pi_{I}}{\partial A_{0}}+b_{C_{u}}(t) \frac{\partial C_{u}}{\partial A_{0}}+b_{H}(t) \frac{\partial H}{\partial A_{0}}
$$

where the coefficients $b_{i}(t)$ are defined by the transition from (25) to (26).

And, likewise, for unhealthy consumption the comparative dynamic effect of initial wealth is obtained from (10):

$$
\begin{aligned}
& {\left[\frac{\partial^{2} U}{\partial C_{u}^{2}}-q_{A}(0) \pi_{I}(t) \frac{\partial^{2} d}{\partial C_{u}^{2}} H(t) e^{(\beta-\delta) t}\right] \frac{\partial C_{u}}{\partial A_{0}} } \\
= & {\left[\frac{1}{q_{A}(0)} \frac{\partial U}{\partial C_{u}}\right] \times \frac{\partial q_{A}(0)}{\partial A_{0}} } \\
+ & {\left[q_{A}(0) \frac{\partial d}{\partial C_{u}} H(t) e^{(\beta-\delta) t}\right] \times \frac{\partial \pi_{I}}{\partial A_{0}} } \\
+ & {\left[q_{A}(0) \pi_{I}(t) \frac{\partial^{2} d}{\partial C_{h} \partial C_{u}} H(t) e^{(\beta-\delta) t}-\frac{\partial^{2} U}{\partial C_{h} \partial C_{u}}\right] \times \frac{\partial C_{h}}{\partial A_{0}} } \\
+ & {\left[q_{A}(0) \pi_{I}(t) \frac{\partial d}{\partial C_{u}} e^{(\beta-\delta) t}-\frac{\partial^{2} U}{\partial H \partial C_{u}}\right] \times \frac{\partial H}{\partial A_{0}} . }
\end{aligned}
$$

Or,

$$
\frac{\partial C_{u}}{\partial A_{0}} \equiv c_{q}(t) \frac{\partial q_{A}(0)}{\partial A_{0}}+c_{\pi}(t) \frac{\partial \pi_{I}}{\partial A_{0}}+c_{C_{h}}(t) \frac{\partial C_{h}}{\partial A_{0}}+c_{H}(t) \frac{\partial H}{\partial A_{0}}
$$


where the coefficients $c_{i}(t)$ are defined by the transition from (27) to (28).

Now substitute (26) into (28) and vice versa to obtain

$$
\begin{aligned}
\frac{\partial C_{h}}{\partial A_{0}} & =\frac{b_{q}(t)+b_{C_{u}}(t) c_{q}(t)}{1-c_{C_{h}}(t) b_{C_{u}}(t)} \times \frac{\partial q_{A}(0)}{\partial A_{0}} \\
& +\frac{b_{\pi}(t)+b_{C_{u}}(t) c_{\pi}(t)}{1-c_{C_{h}}(t) b_{C_{u}}(t)} \times \frac{\partial \pi_{I}}{\partial A_{0}} \\
& +\frac{b_{H}(t)+b_{C_{u}}(t) c_{H}(t)}{1-c_{C_{h}}(t) b_{C_{u}}(t)} \times \frac{\partial H}{\partial A_{0}}
\end{aligned}
$$

and

$$
\begin{aligned}
\frac{\partial C_{u}}{\partial A_{0}} & =\frac{c_{q}(t)+c_{C_{h}}(t) b_{q}(t)}{1-c_{C_{h}}(t) b_{C_{u}}(t)} \times \frac{\partial q_{A}(0)}{\partial A_{0}} \\
& +\frac{c_{\pi}(t)+c_{C_{h}}(t) b_{\pi}(t)}{1-c_{C_{h}}(t) b_{C_{u}}(t)} \times \frac{\partial \pi_{I}}{\partial A_{0}} \\
& +\frac{c_{H}(t)+c_{C_{h}}(t) b_{H}(t)}{1-c_{C_{h}}(t) b_{C_{u}}(t)} \times \frac{\partial H}{\partial A_{0}} .
\end{aligned}
$$

Equations (29) and (30) show that the effect of variation in initial wealth $A_{0}$ can be decomposed into its effect on (i) lifetime wealth, $q_{A}(0)$, (ii) health investment, $\pi_{I}(t)$, and (iii) health, $H(t)$. We assume diminishing returns to wealth, i.e. poor individuals derive greater marginal life-time utility benefits from an additional increment of wealth than wealthier individuals: $\frac{\partial q_{A}(0)}{\partial A_{0}}<0$ (a standard assumption made in the literature). The signs of $\partial \pi_{I}(t) / \partial A_{0}$ and of $\partial H(t) / \partial A_{0}$ in (29) and (30) are not known a priori, and we will explore them further below.

For the control variable health investment, the comparative dynamic effect of initial wealth $A_{0}$ is obtained from (5):

$$
\begin{aligned}
\frac{\partial}{\partial t} \frac{\partial \pi_{I}}{\partial A_{0}} & =\left[\frac{1}{q_{A}(0)^{2}} \frac{\partial U}{\partial H} e^{-(\beta-\delta) t}\right] \times \frac{\partial q_{A}(0)}{\partial A_{0}} \\
& +[d(t)+\delta] \times \frac{\partial \pi_{I}}{\partial A_{0}} \\
& +\left[\pi_{I}(t) \frac{\partial d}{\partial C_{h}}-\frac{1}{q_{A}(0)} \frac{\partial^{2} U}{\partial C_{h} \partial H} e^{-(\beta-\delta) t}\right] \times \frac{\partial C_{h}}{\partial A_{0}} \\
& +\left[\pi_{I}(t) \frac{\partial d}{\partial C_{u}}-\frac{1}{q_{A}(0)} \frac{\partial^{2} U}{\partial C_{u} \partial H} e^{-(\beta-\delta) t}\right] \times \frac{\partial C_{u}}{\partial A_{0}} \\
& +\left[-\frac{1}{q_{A}(0)} \frac{\partial^{2} U}{\partial H^{2}} e^{-(\beta-\delta) t}-\frac{\partial^{2} Y}{\partial H^{2}}\right] \times \frac{\partial H}{\partial A_{0}}
\end{aligned}
$$

Or,

$$
\frac{\partial}{\partial t} \frac{\partial \pi_{I}}{\partial A_{0}} \equiv a_{q}(t) \frac{\partial q_{A}(0)}{\partial A_{0}}+a_{\pi}(t) \frac{\partial \pi_{I}}{\partial A_{0}}+a_{C_{h}}(t) \frac{\partial C_{h}}{\partial A_{0}}+a_{C_{u}}(t) \frac{\partial C_{u}}{\partial A_{0}}+a_{H}(t) \frac{\partial H}{\partial A_{0}},
$$


where the coefficients $a_{i}(t)$ are defined by the transition from (31) to (32).

Substituting (29) and (30) into (32) we arrive at

$$
\begin{aligned}
& \frac{\partial}{\partial t} \frac{\partial \pi_{I}}{\partial A_{0}} \\
= & \left\{a_{q}(t)+\frac{a_{C_{h}}(t)\left[b_{q}(t)+b_{C_{u}}(t) c_{q}(t)\right]}{1-c_{C_{h}}(t) b_{C_{u}}(t)}+\frac{a_{C_{u}}(t)\left[c_{q}(t)+c_{C_{h}}(t) b_{q}(t)\right]}{1-c_{C_{h}}(t) b_{C_{u}}(t)}\right\} \times \frac{\partial q_{A}(0)}{\partial A_{0}} \\
+ & \left\{a_{\pi}(t)+\frac{a_{C_{h}}(t)\left[b_{\pi}(t)+b_{C_{u}}(t) c_{\pi}(t)\right]}{1-c_{C_{h}}(t) b_{C_{u}}(t)}+\frac{a_{C_{u}}(t)\left[c_{\pi}(t)+c_{C_{h}}(t) b_{\pi}(t)\right]}{1-c_{C_{h}}(t) b_{C_{u}}(t)}\right\} \times \frac{\partial \pi_{I}}{\partial A_{0}} \\
+ & \left\{a_{H}(t)+\frac{a_{C_{h}}(t)\left[b_{H}(t)+b_{C_{u}}(t) c_{H}(t)\right]}{1-c_{C_{h}}(t) b_{C_{u}}(t)}+\frac{a_{C_{u}}(t)\left[c_{H}(t)+c_{C_{h}}(t) b_{H}(t)\right]}{1-c_{C_{h}}(t) b_{C_{u}}(t)}\right\} \times \frac{\partial H}{\partial A_{0}}(33)
\end{aligned}
$$

The dynamic equation for health (2) can be rewritten in terms of $\pi_{I}(t)$ using the definition of $\pi_{I}(t)$ in (6) as follows:

$$
\begin{aligned}
\frac{\partial H}{\partial t} & =I(t)^{\alpha}-d(t) H(t) \\
& =\left(\frac{\alpha \mu_{I}(t) \pi_{I}(t)}{p_{I}(t)}\right)^{\frac{\alpha}{1-\alpha}}-d(t) H(t) .
\end{aligned}
$$

Taking the derivative with respect to $A_{0}$, it follows that

$$
\begin{aligned}
\frac{\partial}{\partial t} \frac{\partial H}{\partial A_{0}} & =\frac{\alpha}{1-\alpha}\left(\frac{\alpha \mu_{I}(t)}{p_{I}(t)}\right)^{\frac{\alpha}{1-\alpha}} \pi_{I}(t)^{\frac{2 \alpha-1}{1-\alpha}} \times \frac{\partial \pi_{I}}{\partial A_{0}} \\
& -\frac{\partial d}{\partial C_{h}} H(t) \times \frac{\partial C_{h}}{\partial A_{0}} \\
& -\frac{\partial d}{\partial C_{u}} H(t) \times \frac{\partial C_{u}}{\partial A_{0}} \\
& -d(t) \times \frac{\partial H}{\partial A_{0}} .
\end{aligned}
$$

Or,

$$
\frac{\partial}{\partial t} \frac{\partial H}{\partial A_{0}} \equiv d_{\pi}(t) \frac{\partial \pi_{I}}{\partial A_{0}}+d_{C_{h}}(t) \frac{\partial C_{h}}{\partial A_{0}}+d_{C_{u}}(t) \frac{\partial C_{u}}{\partial A_{0}}+d_{H}(t) \frac{\partial H}{\partial A_{0}} .
$$

Substitute (29) and (30) into (36) to obtain

$$
\begin{aligned}
& \frac{\partial}{\partial t} \frac{\partial H}{\partial A_{0}} \\
= & \left\{\frac{d_{C_{h}}(t)\left[b_{q}(t)+b_{C_{u}}(t) c_{q}(t)\right]}{1-c_{C_{h}}(t) b_{C_{u}}(t)}+\frac{d_{C_{u}}(t)\left[c_{q}(t)+c_{C_{h}}(t) b_{q}(t)\right]}{1-c_{C_{h}}(t) b_{C_{u}}(t)}\right\} \times \frac{\partial q_{A}(0)}{\partial A_{0}} \\
+ & \left\{d_{\pi}(t)+\frac{d_{C_{h}}(t)\left[b_{\pi}(t)+b_{C_{u}}(t) c_{\pi}(t)\right]}{1-c_{C_{h}}(t) b_{C_{u}}(t)}+\frac{d_{C_{u}}(t)\left[c_{\pi}(t)+c_{C_{h}}(t) b_{\pi}(t)\right]}{1-c_{C_{h}}(t) b_{C_{u}}(t)}\right\} \times \frac{\partial \pi_{I}}{\partial A_{0}} \\
+ & \left\{d_{H}(t)+\frac{d_{C_{h}}(t)\left[b_{H}(t)+b_{C_{u}}(t) c_{H}(t)\right]}{1-c_{C_{h}}(t) b_{C_{u}}(t)}+\frac{d_{C_{u}}(t)\left[c_{H}(t)+c_{C_{h}}(t) b_{H}(t)\right]}{1-c_{C_{h}}(t) b_{C_{u}}(t)}\right\} \times \frac{\partial H}{\partial A_{0}}(37)
\end{aligned}
$$


Equations (33) and (37) contain many higher-order terms and are intractable to work with. For this reason, we make the simplifying assumption that first-order terms dominate higher-order terms. In other words, that terms such as for example $b_{C_{u}}(t) c_{q}(t)$ (which captures the indirect effect of wealth on healthy consumption through the effect that wealth has on unhealthy consumption and unhealthy consumption in turn has on healthy consumption) are smaller than $b_{q}(t)$ (which captures the direct effect of wealth on healthy consumption).

The comparative dynamic effect of initial wealth on healthy and unhealthy consumption is under this assumption approximated by equations (12) and (13), respectively.

The equation for the change in health investment reduces to

$$
\frac{\partial}{\partial t} \frac{\partial \pi_{I}}{\partial A_{0}} \approx a_{q}(t) \frac{\partial q_{A}(0)}{\partial A_{0}}+a_{\pi}(t) \frac{\partial \pi_{I}}{\partial A_{0}}+a_{H}(t) \frac{\partial H}{\partial A_{0}}
$$

where it can be inferred that $a_{q}(t)>0, a_{\pi}(t)>0$, and $a_{H}(t)>0$.

The expression for the change in health is

$$
\frac{\partial}{\partial t} \frac{\partial H}{\partial A_{0}} \approx d_{\pi}(t) \times \frac{\partial \pi_{I}}{\partial A_{0}}+d_{H}(t) \times \frac{\partial H}{\partial A_{0}},
$$

where $d_{\pi}(t)>0$ and $d_{H}(t)<0$.

Using the comparative dynamic results in (38) and (39) we are ready to predict the sign of $\frac{\partial \pi_{I}(t)}{\partial A_{0}}$ and $\frac{\partial H(t)}{\partial A_{0}}$ using the phase diagram in Figure 1. The figure shows on the y-axis the variation of the marginal cost of health investment with respect to initial wealth $\frac{\partial \pi_{I}}{\partial A_{0}}$ and on the $\mathrm{x}$-axis the variation of health with respect to initial wealth $\frac{\partial H}{\partial A_{0}}$. The phase diagram is divided into four quadrants, where quadrant I corresponds to $\frac{\partial \pi_{I}}{\partial A_{0}}>0$ and $\frac{\partial H}{\partial A_{0}}>0$, quadrant II to $\frac{\partial \pi_{I}}{\partial A_{0}}<0$ and $\frac{\partial H}{\partial A_{0}}>0$, and so on. Associated with each point in the phase diagram is a direction of motion, represented by the grey block arrows.

Since we know the signs of the coefficients in (38) and (39), and have made the common assumption that $\frac{\partial q_{A}(0)}{\partial A_{0}}<0$, we can predict the sign of $\frac{\partial}{\partial t} \frac{\partial \pi_{I}}{\partial A_{0}}$ and $\frac{\partial}{\partial t} \frac{\partial H}{\partial A_{0}}$, i.e., the direction of motion, in all four quadrants of the phase diagram.

For example, consider the horizontal axis on the left-hand side of the figure corresponding to $\frac{\partial \pi_{I}}{\partial A_{0}}=0$ and $\frac{\partial H}{\partial A_{0}}<0$. Equation (38) now reduces to

$$
\frac{\partial}{\partial t} \frac{\partial \pi_{I}}{\partial A_{0}}=a_{q}(t) \frac{\partial q_{A}(0)}{\partial A_{0}}+a_{H}(t) \frac{\partial H}{\partial A_{0}} .
$$

Since $a_{q}(t)>0, \frac{\partial q_{A}(0)}{\partial A_{0}}<0, a_{H}(t)>0$, and $\frac{\partial H}{\partial A_{0}}<0$ we have $\frac{\partial}{\partial t} \frac{\partial \pi_{I}}{\partial A_{0}}<0$. Likewise, equation (39) reduces to

$$
\frac{\partial}{\partial t} \frac{\partial H}{\partial A_{0}}=d_{H}(t) \times \frac{\partial H}{\partial A_{0}},
$$


where $d_{H}(t)<0$ and $\frac{\partial H}{\partial A_{0}}<0$, and hence $\frac{\partial}{\partial t} \frac{\partial H}{\partial A_{0}}>0$. Since $\frac{\partial}{\partial t} \frac{\partial \pi_{I}}{\partial A_{0}}<0$ and $\frac{\partial}{\partial t} \frac{\partial H}{\partial A_{0}}>0$ the direction of motion for points on the horizontal axis for negative values of $\frac{\partial H}{\partial A_{0}}$ is in the Southeastern direction, as represented by the grey block arrow. For positive values of $\frac{\partial H}{\partial A_{0}}$ the direction of motion for $\frac{\partial \pi_{I}}{\partial A_{0}}$ is ambiguous while $\frac{\partial}{\partial t} \frac{\partial H}{\partial A_{0}}$ is negative, as represented by the double block arrow. Note that for small values of $\frac{\partial H}{\partial A_{0}}$ the direction of motion for $\frac{\partial \pi_{I}}{\partial A_{0}}$ is toward lower values (toward the South) whereas for larger values of $\frac{\partial H}{\partial A_{0}}$ the direction of motion for $\frac{\partial \pi_{I}}{\partial A_{0}}$ is toward higher values (toward the North). In a similar vein the direction of motion in other parts of the phase diagram can be determined, as shown by the remaining block arrows.

We can infer the optimal route over the lifecycle once we know the start and end point. These are provided by the initial conditions and the transversality conditions. Since both initial health $H(0)=H_{0}$ and end-of-life health $H(T)=H_{\text {min }}$ are fixed, it follows that $\frac{\partial H(0)}{\partial A_{0}}=\frac{\partial H(T)}{\partial A_{0}}=0$. In the phase diagram this implies that any admissible path should begin and end on the vertical axis.

Now consider a path that starts on the vertical axis, but below the horizontal axis. Any path will move into the Southwestern quadrant (quadrant III), and will stay there indefinitely, as indicated by the dotted line, drawn for illustrative purposes. Because such trajectories will never return to the vertical axis we can rule out any solutions associated with $\frac{\partial \pi_{I}(0)}{\partial A_{0}}<0$. In contrast, paths starting at the vertical axis but above the horizontal axis, could return to the vertical axis in finite time if they cross the horizontal axis and enter quadrant IV at some point over the lifecycle. An example trajectory is shown for illustrative purposes.

From this analysis we conclude that $\frac{\partial \pi_{I}(t)}{\partial A_{0}} \geq 0$, at least initially, and $\frac{\partial H(t)}{\partial A_{0}} \geq 0 \quad \forall t$. Hence, higher initial wealth boosts health investment initially, leading to a higher health stock throughout life, but eventually health investment falls below the unperturbed (original) path after some age. The prediction that health investment falls below the original path after some age is due to the assumption that life span $T$ is fixed. In such a model, health investment cannot be higher throughout life, as this would be associated with a higher health stock at every age, violating the transversality condition that $H(T)=H_{\min }$. It can be shown that if the life span $T$ is endogenous and free, higher initial assets are associated with $\frac{\partial H(t)}{\partial A_{0}}>0 \quad \forall t$ and length of life is extended (see Galama and Van Kippersluis (2010) for details). 


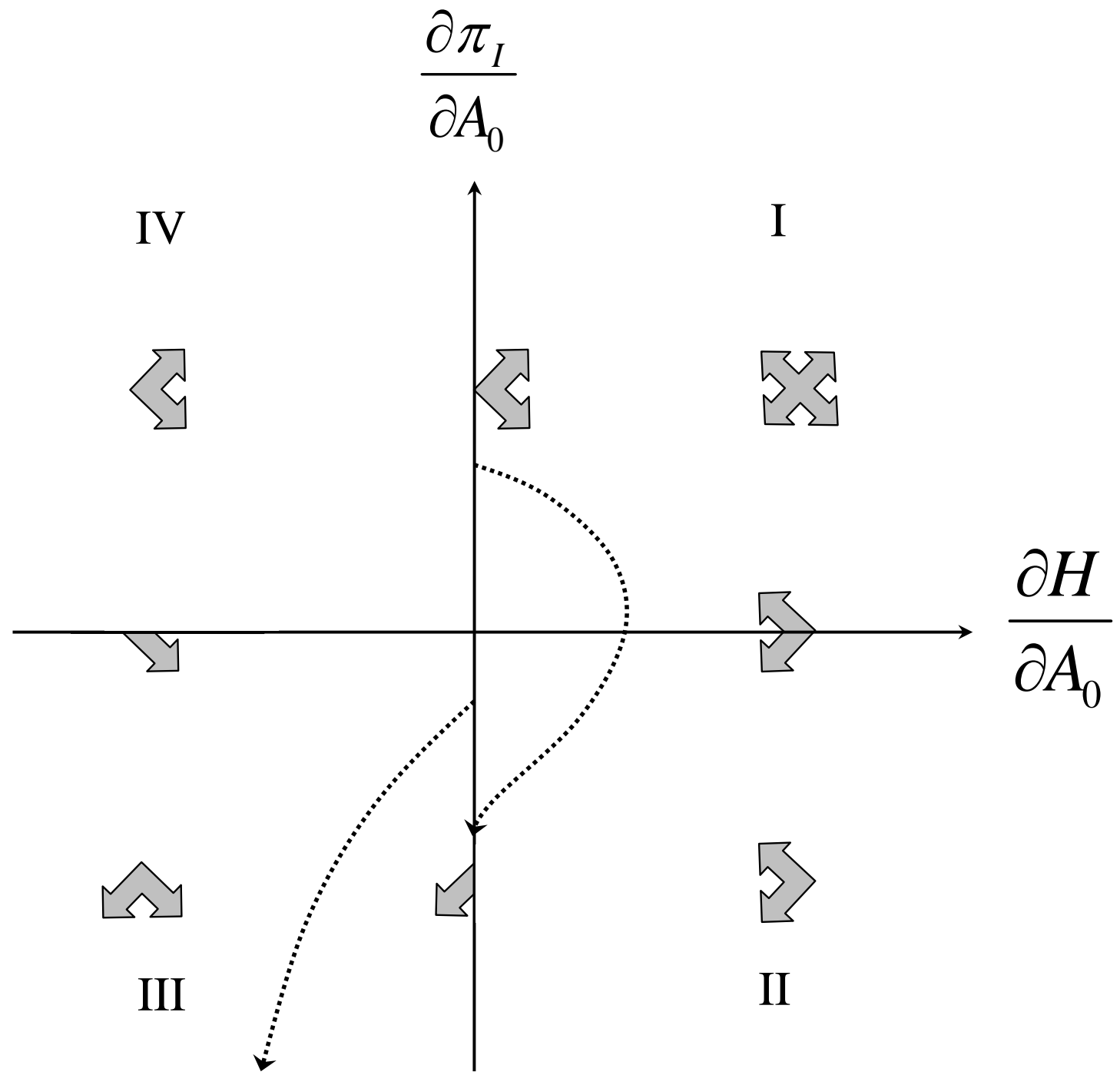

Figure 1: Phase diagram. 


\section{Tables}

Table C.1: Variables in the BHPS

\begin{tabular}{|c|c|}
\hline Variable & Unit \\
\hline \multicolumn{2}{|l|}{ Dependent variables } \\
\hline Food Expenditures & 12 categories $-1(<£ 10), 2(£ 10-19), 3(£ 20-29), 4(£ 30-39), 5(£ 40-49), 6(£ 50-59)$ \\
\hline$(£$ per month) & $7(£ 60-79), 8(£ 80-99), 9(£ 100-119), 10(£ 120-139), 11(£ 140-159), 12(\geq £ 160) ;$ in 2005 British pounds \\
\hline Smoking & Binary: 0 if not smoking, 1 if smoking currently \\
\hline Number of Cigarettes & Continuous, per day \\
\hline Drinking Out & $\begin{array}{l}5 \text { categories }-1 \text { (Never, almost never), } 2 \text { (Once a year or less), } 3 \text { (Several times a year), } \\
4 \text { (At least once a month), } 5 \text { (At least once a week) }\end{array}$ \\
\hline Sports & 5 categories -1 (Never, almost never), 2 (Once a year or less), 3 (Several times a year), \\
\hline & 4 (At least once a month), 5 (At least once a week) \\
\hline \multicolumn{2}{|l|}{ Independent variables } \\
\hline Household Wealth $(£)$ & Continuous - only available in 2000,2005 ; in 2005 British pounds \\
\hline Lottery Winnings & Binary: 1 if won the lottery, 0 if not \\
\hline Amount Lottery Won $(£)$ & Continuous, in 2005 British pounds \\
\hline \multicolumn{2}{|r|}{ 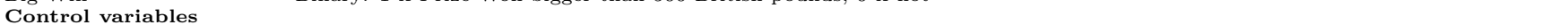 } \\
\hline Household Income $(£)$ & Continuous, annual gross, in 2005 British pounds \\
\hline Age & $\begin{array}{l}\text { Continuous, years } \\
\text { Cross, in } 2000 \text { Dritisn poundas }\end{array}$ \\
\hline Sex & Binary: 0 if female, 1 if male \\
\hline Region & $\begin{array}{l}19 \text { regions }-1 \text { (Inner London), } 2 \text { (Outer London), } 3 \text { (Rest of South East), } 4 \text { (South West), } 5 \text { (East Anglia) } \\
6 \text { (East Midlands), } 7 \text { (West Midlands Conurbation), } 8 \text { (Rest of West Midlands), } 9 \text { (Greater Manchester) } \\
10 \text { (Merseyside), } 11 \text { (Rest of North West), } 12 \text { (South Yorkshire), } 13 \text { (West Yorkshire) }\end{array}$ \\
\hline & $\begin{array}{l}14 \text { (Rest of Yorks \& Humberside), } 15 \text { (Tyne \& Wear), } 16 \text { (Rest of North), } 17 \text { (Wales), } 18 \text { (Scotland), and } 19 \text { (Northern Ireland) } \\
\text { Continuous }\end{array}$ \\
\hline Number of Children & Continuous \\
\hline Level of Education & $\begin{array}{l}13 \text { categories - } 1 \text { (Higher Degree), } 2 \text { (First Degree), } 3 \text { (Teaching Qualification), } 4 \text { (Other Higher Qualification), } \\
5 \text { (Nursing Qualification), } 6 \text { (GCE A Levels), } 7 \text { (GCE O Levels or Equivalent), } \\
8 \text { (Commercial Qualification, No O Levels), } 9 \text { (CSE Grade 2-5, Scottish Grade 4-5), } \\
10 \text { (Apprenticeship), } 11 \text { (Other Qualification), } 12 \text { (No Qualification), } 13 \text { (Still At School, no Qualification) }\end{array}$ \\
\hline Health Status & 5 categories -1 (Excellent), 2 (Good), 3 (Fair), 4 (Poor), 5 (Very Poor) \\
\hline Marital Status & 7 categories -1 (Married), 2 (Separated), 3 (Divorced), 4 (Widowed), 5 (Never married), \\
\hline Employment Status & $\begin{array}{l}10 \text { categories }-1 \text { (Self-employed), } 2 \text { (Employed), } 3 \text { (Unemployed), } 4 \text { (Retired), } 5 \text { (Maternity leave), } \\
6 \text { (Family care), } 7 \text { (Full-time student), } 8 \text { (Disabled), } 9 \text { (Government training scheme), } 10 \text { (Other) }\end{array}$ \\
\hline
\end{tabular}


Table C.2: Variables in the HRS

\begin{tabular}{|c|c|}
\hline Variable & Unit \\
\hline \multicolumn{2}{|l|}{ Dependent variables } \\
\hline Food Expenditures $(\$)$ & Continuous, in 2005 US dollars, per week \\
\hline Smoking & Binary: 0 if not smoking, 1 if smoking currently \\
\hline Number of Cigarettes & Continuous, per day \\
\hline Drinking & Binary: 0 if does not drink, 1 if drinks \\
\hline Number of Drinks & Continuous, weekly \\
\hline Heavy Drinking & Binary: 0 if less than 3 drinks on an occasion, 1 if more \\
\hline Light Physical Activity & $\begin{array}{l}5 \text { categories: - 1) Never, 2), } 1 \text { to } 3 \text { times per month, 3) Once per week, } \\
\text { 4) Less than once per week, 5) Every day }\end{array}$ \\
\hline Out-of-Pocket Medical Expenditures (\$) & Continuous, in 2005 US dollars, since last wave \\
\hline \multicolumn{2}{|l|}{ Independent variables } \\
\hline Household Wealth $(\$)$ & Continuous, in 2005 US dollars \\
\hline Inheritance & Binary: 0 if no inheritance, 1 if received inheritance in past two years \\
\hline Amount Inherited (\$) & Continuous, in US dollars \\
\hline Big Inheritance & Binary: 0 if Amount Inherited $<\$ 10,000,1$ if $\geq \$ 10,000$ \\
\hline \multicolumn{2}{|r|}{ 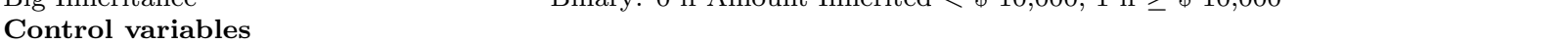 } \\
\hline Household Income $(\$)$ & Continuous, annual gross, 2005 US dollars \\
\hline Age & Continuous, in years \\
\hline Sex & Binary: 0 if female, 1 if male \\
\hline Race & 3 categories - 1) White/Caucasian, 2) Black/African American, 3) Other \\
\hline Census Region & 5 categories - 1) Northeast, 2) Midwest, 3) South, 4) West, 5) Other \\
\hline Household Size & Continuous \\
\hline Number of Children & Continuous \\
\hline Years of Education & Continuous, in years of schooling \\
\hline Health Status & 5 categories - 1) Excellent, 2) Very Good, 3) Good, 4) Fair, 5) Poor \\
\hline Marital Status & $\begin{array}{l}8 \text { categories - 1) Married, 2) Married, spouse absent, 3) Partnered, 4) Separated, } \\
\text { 5) Divorced, 6) Separated/Divorced, 7) Widow, 8) Never married }\end{array}$ \\
\hline Employment Status & Binary: 0 if not working for pay, 1 if working for pay \\
\hline Ever Smoked & Binary: 0 if never smoked, 1 if ever smoked \\
\hline Health Insurance & Binary: 0 if no health insurance, 1 if health insurance \\
\hline Mother Died & Binary: 1 if mother died in the wave, 0 if not \\
\hline Father Died & Binary: 1 if father died in the wave, 0 if not \\
\hline Mother in Law Died & Binary: 1 if mother in law died in the wave, 0 if not \\
\hline Father in Law Died & Binary: 1 if father in law died in the wave, 0 if not \\
\hline Widowed & Binary: 1 if widowed in the wave, 0 if not \\
\hline
\end{tabular}


Table C.3: Benchmark OLS estimates

\begin{tabular}{|c|c|c|c|}
\hline Outcome & $\begin{array}{l}\text { OLS Household } \\
\text { Wealth }\end{array}$ & $\begin{array}{c}\text { OLS Big } \\
\text { Lottery Won }\end{array}$ & $\begin{array}{l}\text { OLS Log Amount } \\
\text { Lottery Won }\end{array}$ \\
\hline \multicolumn{4}{|l|}{ BHPS } \\
\hline Log Food Expenditures & $0.0518^{* * *}$ & $0.2678^{* * *}$ & $0.0577^{* * *}$ \\
\hline$N=134,829$ & $(0.0044)$ & $(0.0383)$ & $(0.0087)$ \\
\hline Smoking & $-0.0183^{* * *}$ & 0.0364 & $0.0108^{* * *}$ \\
\hline$N=134,829$ & $(0.0013)$ & $(0.0222)$ & $(0.0038)$ \\
\hline Log Number of Cigarettes & $-0.0204^{* * *}$ & 0.0914 & $0.0350^{* * *}$ \\
\hline$N=34,678$ & $(0.0041)$ & $(0.0662)$ & $(0.0121)$ \\
\hline Drinking Out & 0.0066 & $0.2486^{* * *}$ & $0.0701^{* * *}$ \\
\hline$N=54,247$ & $(0.0056)$ & $(0.0725)$ & $(0.0121)$ \\
\hline Sports & $0.0465^{* * *}$ & 0.0662 & 0.0224 \\
\hline$N=42,625$ & $(0.0063)$ & $(0.0935)$ & $(0.0152)$ \\
\hline Outcome & $\begin{array}{l}\text { OLS Household } \\
\text { Wealth }\end{array}$ & $\begin{array}{c}\text { OLS Big } \\
\text { Amount Inherited }\end{array}$ & $\begin{array}{l}\text { OLS Log Amount } \\
\text { Inherited }\end{array}$ \\
\hline \multicolumn{4}{|l|}{ HRS } \\
\hline $\begin{array}{l}\text { Log Food Expenditures } \\
\quad N=77,720\end{array}$ & $\begin{array}{l}0.0370^{* * *} \\
(0.0033)\end{array}$ & $\begin{array}{c}0.0767 \\
(0.0629)\end{array}$ & $\begin{array}{l}0.0382^{* *} \\
(0.0183)\end{array}$ \\
\hline $\begin{array}{l}\text { Smoking } \\
\qquad N=118,604\end{array}$ & $\begin{array}{l}-0.0080^{* * *} \\
(0.0009)\end{array}$ & $\begin{array}{c}-0.0322^{* *} \\
(0.0157)\end{array}$ & $\begin{array}{c}-0.0004 \\
(0.0031)\end{array}$ \\
\hline Log Number of Cigarettes & 0.0009 & $-0.4276^{* * *}$ & $-0.0581^{* *}$ \\
\hline$N=16,034$ & $(0.0042)$ & $(0.1040)$ & $(0.0285)$ \\
\hline Drinking & $0.0147^{* * *}$ & $0.0406^{* *}$ & 0.0064 \\
\hline$N=118,604$ & $(0.0010)$ & $(0.0204)$ & $(0.0047)$ \\
\hline Log Number of Drinks & $0.0173^{* * *}$ & $0.0799^{*}$ & 0.0100 \\
\hline$N=108,333$ & $(0.0018)$ & $(0.0467)$ & $(0.0103)$ \\
\hline Heavy Drinking & -0.0006 & 0.0037 & 0.0027 \\
\hline$N=108,333$ & $(0.0005)$ & $(0.0112)$ & $(0.0026)$ \\
\hline Light Physical Activity & $0.0433^{* * *}$ & -0.0634 & -0.0080 \\
\hline$N=57,633$ & $(0.0026)$ & $(0.0535)$ & $(0.0104)$ \\
\hline Log Out-of-pocket Expenditures & $0.2679^{* * *}$ & 0.1295 & $0.0624^{* * *}$ \\
\hline$N=108,333$ & $(0.0080)$ & $(0.1141)$ & $(0.0228)$ \\
\hline
\end{tabular}

Notes: Author's calculations based on the 1997-2008 BHPS and 1992-2010 HRS. For the BHPS analyses employing the log of household wealth, the sample size is reduced to $\mathrm{N}=17,544$, because this measure is only available in the years 2000 and 2005 (first column "OLS Household Wealth" in the top half of the table). All models include the control variables first lag of household income, age, age-squared, sex, race dummies, lagged region dummies, lagged household size, lagged number of children, education, lagged self-reported health, lagged marital status, lagged employment status and interactions between time and region dummies. For the HRS, all models also include controls for ever smoked, health insurance, whether mother died, father died, mother in-law died, or father in-law died and whether widowed since last observation. 